\title{
Telomere length regulation by Rif1 protein from Hansenula polymorpha
}

\author{
${ }^{1}$ Faculty of Chemistry and Belozersky Institute of Physico-Chemical Biology, Lomonosov Moscow \\ State University, Moscow, 119992, Russia. \\ ${ }^{2}$ Center for Magnetic Tomography and Spectroscopy, Faculty of Fundamental Medicine, Lomonosov \\ Moscow State University, Moscow, Russia, 119991.
${ }^{3}$ Center of Life Sciences, Skolkovo Institute of Science and Technology, Moscow, 143026, Russia
${ }^{4}$ Shemyakin-Ovchinnikov Institute of Bioorganic Chemistry of the Russian Academy of Sciences, Moscow, 117997, Russia

*To whom correspondence should be addressed: Alexander N. Malyavko, Lomonosov Moscow State University, Leninskie Gory 1, Bldg. 40, 119992 Moscow, Russia Tel.: 007(495)939-5418; Fax: 007(495)939-3181; E-mail: malyavkoan@gmail.com

\section{ABSTRACT}

Rif1 is a large multifaceted protein involved in various processes of DNA metabolism - from telomere length regulation and replication to double-strand break repair. The mechanistic details of its action, however, are often poorly understood. Here, we report functional characterization of the Rif1 homologue from methylotrophic thermotolerant budding yeast Hansenula polymorpha DL-1. We show that, similar to other yeast species, $H$. polymorpha Rif1 suppresses telomerase-dependent telomere elongation. We uncover two novel modes of Rif1 recruitment at $H$. polymorpha telomeres: via direct DNA binding and through the association with the $\mathrm{Ku}$ heterodimer. Both of these modes (at least partially) require the intrinsically disordered N-terminal extension - a region of the protein present exclusively in yeast species. We also demonstrate that Rif1 binds Stn1 and promotes its accumulation at telomeres in H. polymorpha. 


\section{INTRODUCTION}

31 Chromosomes of most eukaryotic organisms end in distinctive nucleoprotein structures, called telomeres, which are essential for protection of chromosomes from degradation and fusions by the DNA repair machinery (de Lange, 2018). Short G/C-rich telomeric DNA repeats provide a platform for loading of a specific set of telomeric proteins forming complex dynamic assemblies at the ends of the chromosomes. Dividing cells are constantly losing telomeric repeats due to incomplete replication unless counteracted by either recombination or activity of the ribonucleoprotein complex telomerase. Replenishing of telomeric DNA by telomerase is crucial for long-term proliferation of the majority of eukaryotic cell types. This process is highly coordinated, and plenty of positive and negative regulators of telomerase have been identified to date, many of which are components of the telomeric chromatin (Lee et al., 2020; Lim and Cech, 2021; Shay and Wright, 2019).

In budding yeast Saccharomyces cerevisiae, the double-stranded portion of telomeres is bound by Rap1 through its duplicated MYB domain (Henry et al., 1990; Shore and Nasmyth, 1987). Two additional telomeric proteins - Rif1 and Rif2 - are recruited to telomeres via interaction with Rap1 C-terminus (RCT) (Hardy et al., 1992; Wotton and Shore, 1997). Both of them restrict telomerase action and their double deletion (as well as deletion of the RCT) leads to telomere hyperelongation (Teng et al., 2000; Wotton and Shore, 1997). Rap1 also recruits the histone deacetylase complex Sir2/Sir3/Sir4 (through an interaction between Sir4 and RCT) providing the basis for the silencing of telomere-proximal genes (Moretti et al., 1994). The C-terminal portion of Rif1 contains a Rap1-binding motif (Rif1 $\left.1_{\mathrm{RBM}}\right)$ and a tetramerization module (Rif1 $1_{\mathrm{CTD}}$ ), while Rif2 contains two Rap1-binding sites, therefore Rap1/Rif1/Rif2 can form complex DNA-protein structures at the chromosome ends, inhibiting both telomerase recruitment and telomere silencing (Shi et al., 2013). In addition, Rif1 can localize at telomeres in a Rap1-independent fashion through its large HEAT repeats containing N-terminal domain $\left(\operatorname{Rif} 1_{\mathrm{NTD}}\right)$ that exhibits strong affinity to DNA with some preference towards 3'-overhang containing ss-ds junctions (Mattarocci et al., 2017). This binding mode is important for telomerase regulation and attenuation of 
end resection at telomeres. Recently, the ScRif1 $1_{\mathrm{NTD}}$ was proposed to contain an interaction site for a yet unidentified protein partner at telomeres (Shubin et al., 2021).

The single-stranded region of telomeres (3'-overhang) is bound and protected by the Cdc13 protein (Garvik et al., 1995; Lin and Zakian, 1996; Nugent et al., 1996) together with its partners Stn1 and Ten1 (the CST complex) (Grandin, 2001; Grandin et al., 1997; Mersaoui and Wellinger, 2019; Wellinger and Zakian, 2012). Cdc13 is a central hub for telomeric DNA synthesis as it mediates the main pathway of telomerase recruitment (synthesis of the G-strand), as well as assists in loading of the Pol $\boldsymbol{\alpha}$ (synthesis of the C-strand) (Qi and Zakian, 2000; Wellinger and Zakian, 2012). Telomerase recruitment in $S$. cerevisiae also depends on another telomeric complex - the $\mathrm{Ku} 70 / \mathrm{Ku} 80$ heterodimer $(\mathrm{Ku})$ : it binds a stem-loop structure within telomerase RNA and the Sir4 protein at telomeres (Hass and Zappulla, 2015; Peterson et al., 2001; Stellwagen, 2003). In addition, Ku can bind DNA directly and apparently does so at sub-telomeric regions and, perhaps, at the ds-ss junction of the telomere (Larcher et al., 2016; Lopez et al., 2011). Ku loss leads to telomere shortening and Exo1-dependent accumulation of single-stranded telomeric DNA (Bonetti et al., 2010; Boulton, 1996; Gravel, 1998; Polotnianka et al., 1998; Porter et al., 1996).

Almost every telomeric chromatin component plays important roles outside telomeres. Rap1 protein is a central transcription factor, controlling expression of hundreds of genes in budding yeast (Azad and Tomar, 2016). A regulatory role during RNA PolII transcription was recently described for ScCST complex (Calvo et al., 2019). Ku heterodimer is a key component of the non-homologous end joining (NHEJ) machinery (Frit et al., 2019). Rif1 protein binds Glc7 (PP1) phosphatase and this interaction is important for regulation of replication initiation at several origins (Davé et al., 2014; Hiraga et al., 2014; Mattarocci et al., 2014), but not for telomere length control (Shubin and Greider, 2020). Interestingly, this function in replication, but not the telomeric role, is conserved among eukaryotic Rifl homologues (see (Alavi et al., 2021) for a recent review). The only known species outside budding yeast clade which contains Rif1 as a component of "normal" telomeric chromatin is fission yeast Schizosaccharomyces pombe; although SpRif1 is recruited through an interaction with Taz1 protein rather than Rap1 (Kanoh 
and Ishikawa, 2001). Mammalian Rif1 associates with dysfunctional telomeres (and other types of DSB) together with 53BP1, limiting accumulation of ssDNA through a mechanism involving Rev7, the Shieldin complex, CST and Pol $\boldsymbol{\alpha}$, and driving the DSB repair towards NHEJ (Barazas et al., 2018; Chapman et al., 2013; Dev et al., 2018; Di Virgilio et al., 2013; Escribano-Díaz et al., 2013; Gupta et al., 2018; Mirman et al., 2018; Noordermeer et al., 2018; Tomida et al., 2018; Zimmermann et al., 2013). Interestingly, S. cerevisiae Rif1 also localizes to non-telomeric DSBs and promotes NHEJ through its DNA binding NTD, suggesting that Rif1 may be a conserved NHEJ factor (Mattarocci et al., 2017).

The thermotolerant methylotrophic budding yeast species Hansenula polymorpha DL-1 is distantly related to $S$. cerevisiae. Several interesting differences in telomere biology between the two species have already been documented. Rap1 has two paralogues in H. polymorpha (Rap1A and Rap1B) with distinct DNA recognition properties (Malyavko et al., 2019). HpRap1A is located at the subtelomeric regions with no reported telomeric role. HpRap1B is the major telomeric dsDNA binder with the ability to control telomere length, although the primary target of its inhibition appears to be recombination rather than telomerase (Malyavko et al., 2019). The RIF2 gene is absent from H. polymorpha genome (and other yeasts outside Saccharomycetaceae family). A shorter version of Cdc13 protein is present in $H$. polymorpha, which possesses strong affinity for telomeric G-strand in vitro and binds Stn1 protein (Malyavko and Dontsova, 2020). HpCdc13 also interacts HpTERT in the yeast-two-hybrid (Y2H) assay. Here, we explored the conservation of the telomeric roles of Rif1 protein within budding yeast clade by investigating Rif1 function in the telomere maintenance of Hansenula polymorpha. We found that Rif1 restricts telomerase action at $H$. polymorpha telomeres. We demonstrate that the Rif1 N-terminal extension ( Rif $_{\mathrm{NTE}}$ ) - a portion of Rif1 present exclusively in yeast homologues of the protein - is an intrinsically disordered domain with the ability to bind DNA in vitro. We show that this DNA-binding domain helps to recruit Rifl to telomeres. Moreover, we found that the interaction with the $\mathrm{Ku}$ heterodimer is required for Rif1 telomeric localization in H. polymorpha. Finally, we found that the conserved N-terminal domain of HpRif1 binds to HpStn1 protein, and this interaction is crucial for HpStn1 recruitment at telomeres. 


\section{RESULTS}

\section{Rif1 protein regulates telomere length in $H$. polymorpha}

Iterative PSI-BLAST search against NCBI protein database yielded a single plausible $H$. polymorpha

111 Rif1 homologue: the open reading frame HPODL_04218 (UniProt accession number W1QFB8). Amino

112 acid sequence similarity between ScRif1 and HpRif1 is very low (16\% identity), however alignment of 113 multiple budding yeast homologues revealed several conserved elements within HpRif1 (Figure 1A, 114 Supplementary file 1): the RVxF/SILK motif (residues 277-306), the N-terminal HEAT repeats 115 containing domain (Rif1 ${ }_{\mathrm{NTD}}$, residues $\sim 310-1000$ ) and the C-terminal domain (Rifl $1_{\mathrm{CTD}}$, residues $\sim 1475$ -

116 1521). HpRif1 also contains large potentially disordered regions (residues $\sim 1000-1475$ and 1-277). The 117 residues located N-terminally to the RVxF/SILK motif we term N-terminal extension or NTE (residues 118 1-277).

119 To test whether the identified HpRif1 homologue is involved in telomere maintenance, we deleted the 120 RIFl gene and measured telomere length in the mutant strain. We observed markedly elongated 121 telomeres in the Arifl strain (Figure 1B). Concomitant deletion of the RAD52 gene did not influence 122 telomere overelongation in the Arifl strain, whereas deletion of telomerase RNA gene (TER) led to 123 telomere shortening (Figure 1B). The AriflAter double knock-out strain senesced upon continuous 124 propagation, suggesting that Rif1 inhibits telomerase activity at $H$. polymorpha telomeres (Figure 1C). 125 Next, we investigated telomeric localization of HpRif1. We created the RIF1-HA strain expressing 126 HpRifl protein tagged with hemagglutinin epitope (HA) at the C-terminus. Chromatin 127 immunoprecipitated from this strain via anti-HA antibodies was enriched with telomere proximal 128 fragment "TEL" compared to the internal fragment "ALA1", suggesting that Rif1 localizes at $H$. 129 polymorpha telomeres in vivo (Figure 1D). Thus, Rifl is a telomeric protein inhibiting telomerase action in H. polymorpha similar to its $S$. cerevisiae homologue. 

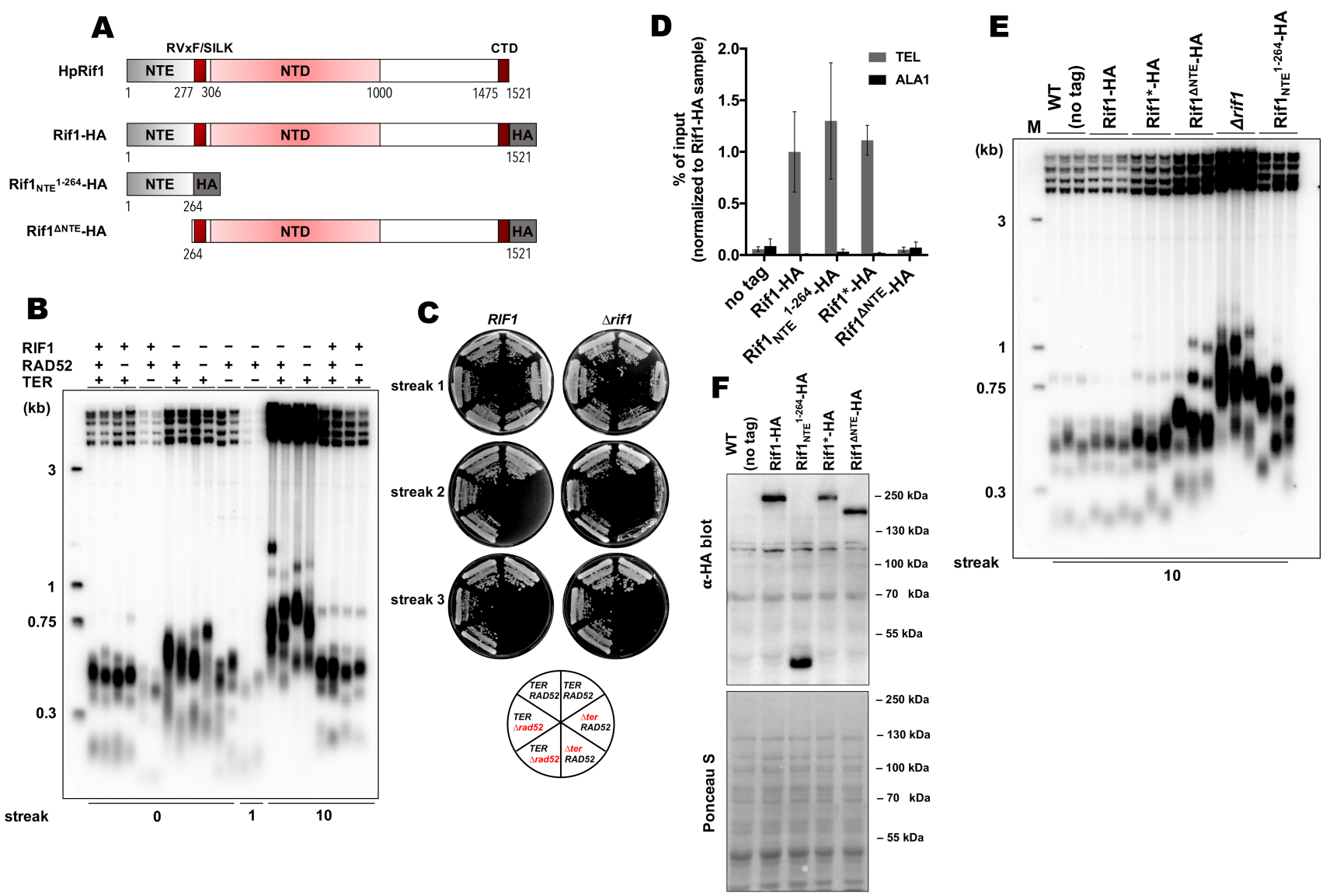

132 Figure 1. Rif1 regulates telomere length in H. polymorpha. (A) Schematic illustration of the domain organization 133 of the full length HpRif1 and HA-tagged Rif1 fragments expressed in H. polymorpha. (B) Southern blot analysis 134 of terminal restriction fragments from the indicated mutant strains. Genomic DNA was isolated from the strains 135 after the $\mathrm{N}^{\text {th }}$ streak (where $\mathrm{N}$ is a number under a lane; each streak is $\sim 20$ generations). " 0 " streak - gDNA was isolated from the colonies on the transformation plate, without additional restreaks. "M" - telomeric DNA containing fragments that served as markers of length (their sizes are indicated on the left of each blot). (C) viability of the strains with the indicated genotypes was monitored during three serial restreaks on YPD agar

139 plates, the plates were photographed after 2 days growth at $37^{\circ} \mathrm{C}$. (D) ChIP analysis. Chromatin from the indicated strains was immunoprecipitated on anti-HA magnetic beads. DNA was analyzed by qPCR with primers targeting 141 either subtelomere region of the right end of chromosome VII ("TEL") or ALA1 gene locus (negative control, “ALA1"). The amount of DNA fragments in the IP samples as a percentage of the input DNA was calculated, the $\%$ of input of the "TEL" Rif1-HA sample was set to 1 . Error bars indicate SD, $n=3$. "Rif1*-HA" - the strain expressing the Rif1-HA protein but in a slightly different background (see METHODS). (E) same as (B) but with different strains. (F) Western blot analysis of the total proteins isolated from the indicated strains using antibodies targeting HA epitope (upper panel). Ponceau S-stained membrane (lower panel) served as a loading control. 


\section{Involvement of Rap1 in recruitment of Rif1 to telomeres}

Telomeric localization of ScRif1 is largely dependent on the interaction with ScRap1, and mutation in the Rif $1_{\mathrm{RBM}}$, located within the C-terminal part of the protein, greatly reduce the amount of telomerebound ScRif1 (Shi et al., 2013). We could not find a similar Rap1-binding motif in the HpRif1 sequence (Supplemental file 1), suggesting that HpRif1 may be recruited at telomeres in a Rap1-independent fashion, or such RBM is located in a different region of the protein. Phenotypic consequences of the ScRif1 loss or removal of the C-terminal domain of ScRap1 are similar, as they both result in the telomerase-dependent telomere overelongation. Telomere elongation in the $\Delta$ rifl strain of $H$. polymorpha appear to rely exclusively on telomerase action (Figure 1B, C). However, we have previously found that elongation of telomeres in the $\mathrm{B}^{1-526}$ strain (expressing C-terminally truncated Rap1B) is largely Rad52-dependent, providing further indication for a Rap1-independent Rif1 function. If Rap1B is not involved in Rif1 recruitment - then Rif1 should not bind to double stranded telomeric DNA. To test this, we constructed the intTEL18 strain of $H$. polymorpha by inserting 18 telomeric repeats upstream of the WSC3 gene on the chromosome I (Figure 1 - figure supplement 1A). As expected, Rap1B binds telomeric repeats with similar efficiency at the internal locus or at the chromosome end (only 2 -fold difference between WSC3 and TEL signals for the intTEL18 strain, Figure 1 - figure supplement 1B). On the contrary, Rif1 association with the internal telomeric repeats is weak and close to the background levels (ChIP WSC3 signal is $\sim 8$-fold lower than TEL, Figure 1 figure supplement 1C). Therefore, we conclude that interaction with Rap1 is not a major determinant of telomeric localization of Rif1 in H. polymorpha.

\section{NTE aids in recruitment of HpRif1 at telomeres}

In an attempt to identify portions of HpRifl important for its telomeric localization, we substituted the RIF1 locus with several HA-tagged C-terminal truncation constructs of Rif1. However, the only variant showing robust expression was the 1-264 fragment containing residues from the NTE region of HpRifl. Quite unexpectedly, we found that this Rif $1_{\mathrm{NTE}}^{1-264}$ fragment can be efficiently recruited to telomeres, 
according to our ChIP experiments (Figure 1D). Moreover, removal of residues 1-264 from HpRif1 $\left(\right.$ Rifl $^{\triangle \mathrm{NTE}}$ ) strongly reduced its ability to associate with telomeric DNA (Figure 1D), and led to telomere elongation (Figure 1E), while having no effect on the accumulation of the protein (Figure 1F). Thus, Rifl $_{\mathrm{NTE}}^{1-264}$ is an important determinant of Rif1 telomeric localization in H. polymorpha.

\section{Rif1 $_{\mathrm{NTE}}^{1-264}$ is intrinsically disordered in H. polymorpha}

Multiple protein sequence alignment of Rif1 homologues from distantly related budding yeasts revealed that N-terminal extensions have no significant similarity (Supplemental file 1), suggesting that Rif1 NTE may not have any conserved folding. Moreover, MetaDisorder prediction (Kozlowski and Bujnicki, 2012) for 1-264 fragment of HpRifl suggests that it lacks any secondary structure (Figure 2A), i.e. $\mathrm{HpRif1}_{\mathrm{NTE}}$ may be unstructured or intrinsically disordered. It is worth noting that during gel-filtration and denaturing gel electrophoresis $28 \mathrm{kDa}$ Rif $1_{\mathrm{NTE}}{ }^{1-264}$ behaves like a protein with higher molecular weight (Figure 2B, C), which is common for many intrinsically disordered proteins (IDPs) (Tompa, 2002). To directly examine the $\operatorname{Rif} 1_{\mathrm{NTE}}^{1-264}$ structure we applied biophysical methods. Circular dichroism spectra of Rif1 ${ }_{\mathrm{NTE}}^{1-264}$ recorded at different temperatures demonstrated that it contains no significant $\alpha$-helical or $\beta$-strand secondary structural elements over this temperature range, as judged by the absence of well-defined peaks in the 215-230 nm region (Figure 2D). The isoelliptical point near $210 \mathrm{~nm}$ is indicative of the equilibrium between left-handed PPII and truly unordered conformation, which has been often observed in CD spectra of IDPs (Bienkiewicz et al., 2000). We also recorded twodimensional ${ }^{1} \mathrm{H}^{-15} \mathrm{~N}$ HSQC NMR spectrum of ${ }^{15} \mathrm{~N}$-labeled Rif $1_{\mathrm{NTE}}{ }^{1-264}$. Narrow chemical shift dispersion of amide protons $(7,8-8,6 \mathrm{ppm})$ in the spectrum confirms that Rif $1_{\mathrm{NTE}}{ }^{1-264}$ is intrinsically disordered (Figure 2E). 
A

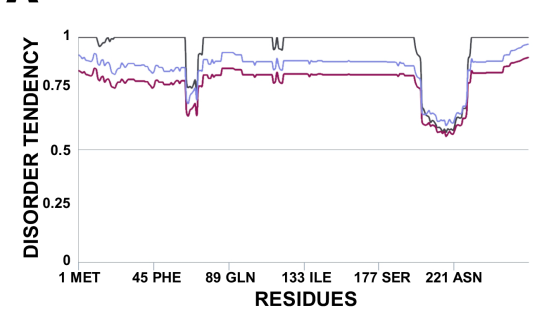

D

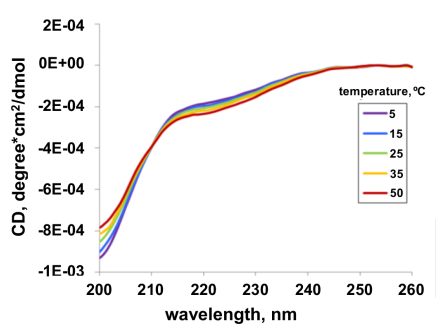

$\mathbf{E}$
B
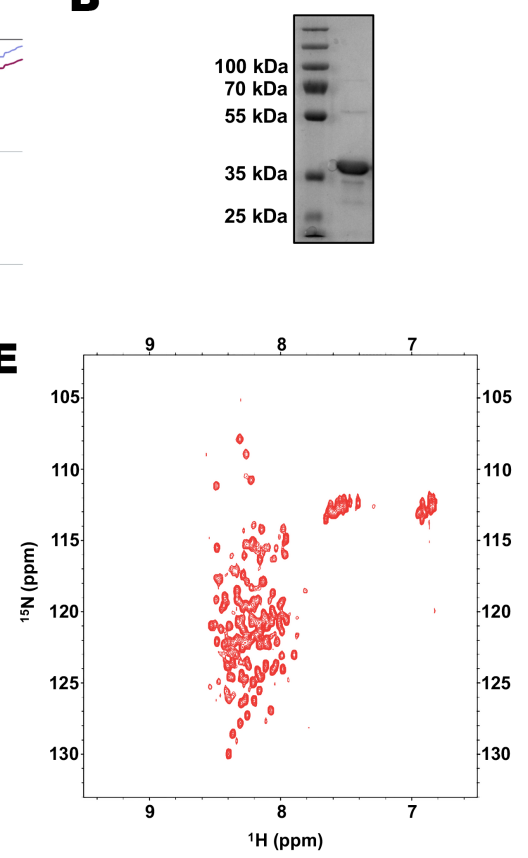

C
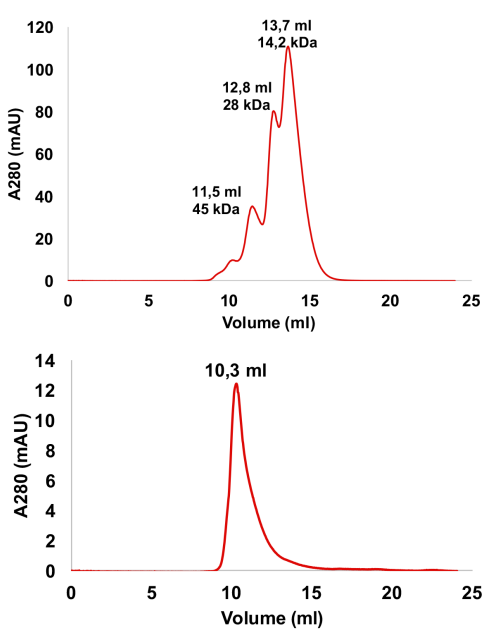

196 Figure 2. N-terminal extension of HpRif1 is intrinsically disordered. (A) Disorder prediction by Metadisorder 197 (Kozlowski and Bujnicki, 2012) for 1-264 fragment of HpRif1 using three different combinations of algorythms: 198 MetaDisorder (black), MetaDisorderMD (purple), MetaDisorderMD2 (blue). All residues with the disorder 199 probability over 0.5 are considered to be disordered. (B) An aliquot of the purified recombinant Rif1 ${ }_{\mathrm{NTE}}{ }^{1-264}$ was analyzed by SDS-PAGE and Coomassie staining. (C) Profiles of size-exclusion chromatography of the mixture of the standard proteins (upper profile) and the recombinant Rif $1_{\mathrm{NTE}}^{1-264}$ (lower profile). (D) Circular dichroism spectra of the Rif $1_{\mathrm{NTE}}{ }^{1-264}$ recorded at $5{ }^{\circ} \mathrm{C}$ (purple), $15{ }^{\circ} \mathrm{C}$ (blue), $25{ }^{\circ} \mathrm{C}$ (green), $35{ }^{\circ} \mathrm{C}$ (yellow) and $50{ }^{\circ} \mathrm{C}$ (red). (E) Two-dimensional ${ }^{1} \mathrm{H}_{-}{ }^{15} \mathrm{~N}$ HSQC NMR spectrum of ${ }^{15} \mathrm{~N}$-labeled Rif1 ${ }_{\mathrm{NTE}}{ }^{1-264}$ recorded at $25{ }^{\circ} \mathrm{C}$. 
Two "clusters" within Rif1 $1_{\mathrm{NTE}}$ are important for DNA binding in vitro and promote telomeric

DNA binding by Rif1 has been demonstrated in several species (including mammals, fission and budding yeasts) (Kanoh et al., 2015; Mattarocci et al., 2017; Moriyama et al., 2018; Sukackaite et al., 2014; Xu et al., 2010). We decided to test whether Rif1-DNA interaction is important for its telomeric localization in H. polymorpha. We divided HpRif1 into several parts (Figure 3A) and expressed them as 6His-S-tagged recombinant proteins in E. coli. After affinity chromatography on Ni-NTA resin we 211 obtained protein preparations significantly enriched with the HpRif1 fragments (Figure 3B). We 212 analyzed the ability of these fragments to interact with ss- and ds-DNA oligonucleotides (FAM-Tel4(G) 213 and FAM-Tel4(GC), respectively) comprised of four telomeric repeats using EMSA. We found that only 214 two fragments (both containing amino acids 1-264 of HpRif1) could bind telomeric DNA (both single215 and double-stranded, Figure 3C). Thus, HpRif1 contains a DNA-binding domain at its N-terminus.

216 The titration experiments revealed that affinities for telomeric ssDNA and dsDNA are very close $\left(\mathrm{K}_{d}{ }^{\text {app }}\right.$ $217 \sim 240 \mathrm{nM}$ for FAM-Tel4(G), and $\mathrm{K}_{\mathrm{d}}{ }^{\text {app }} \sim 430 \mathrm{nM}$ for FAM-Tel4(GC)) in our experimental conditions 218 (Figure 3D, Figure 3 - figure supplement 1A). The competition EMSA confirmed that Rif $1_{\mathrm{NTE}}^{1-264}$ 219 poorly differentiates between Tel4(G), Tel4(C) (C-rich telomeric strand) and Tel4(GC) oligonucleotides 220 (Figure 3E, Figure 3 - figure supplement 1B). However, it also revealed that Rif $1_{\mathrm{NTE}}^{1-264}$ has some 221 preference towards telomeric substrates compared with the G/C-poor DNA oligonucleotides (Figure 3E, 222 Figure 3 - figure supplement 1B, Table 1). 

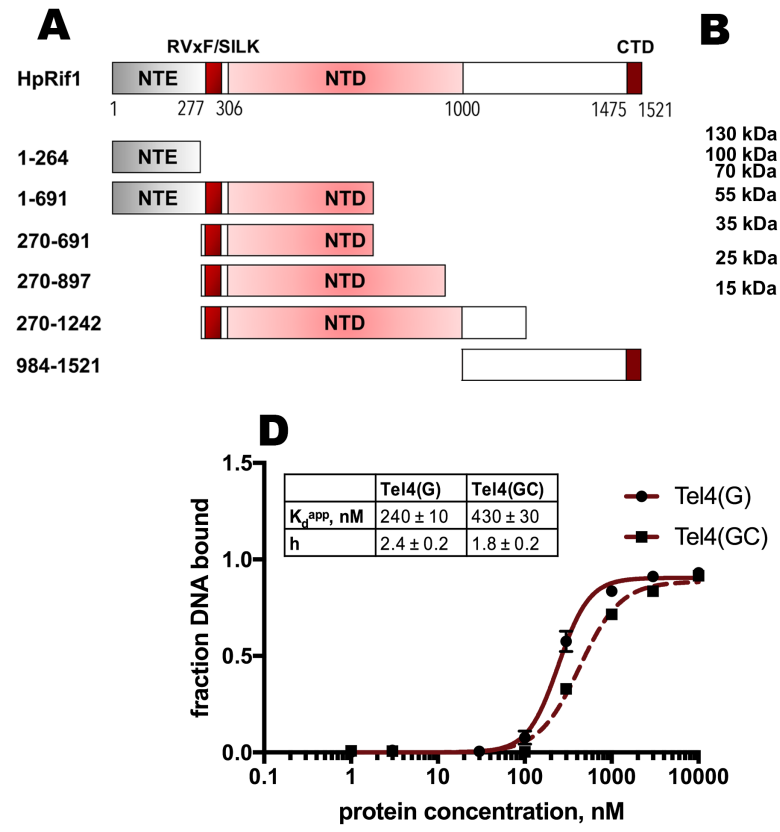
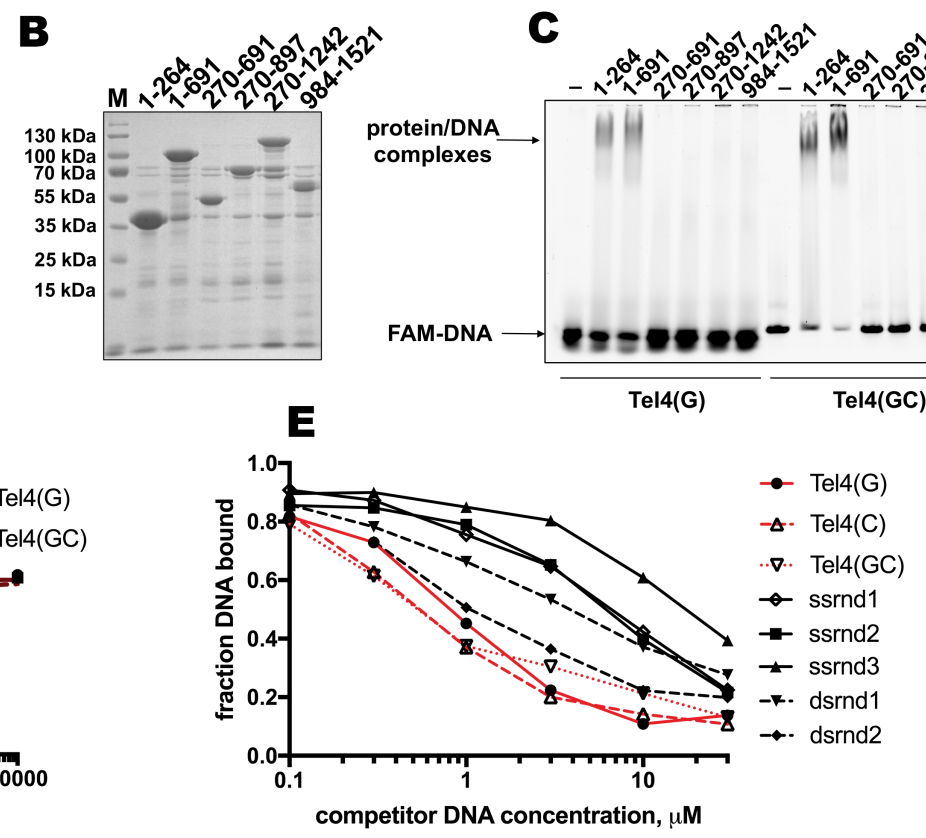

224 Figure 3. Rif $1_{\mathrm{NTE}}^{1-264}$ binds DNA in vitro. (A) Schematic illustration of the 6His-S-tagged Rif1 fragments expressed in E. coli and used in EMSA assays. (B) Aliquots of the Ni-NTA purified fragments were analyzed by SDS- PAGE and Coomassie staining. "M" - protein weight marker. (C) $5 \mu \mathrm{M}$ of the indicated 6 His-S-tagged HpRif1 fragments were subjected to the electrophoretic mobility shift assay, using $0.5 \mu \mathrm{M}$ of either ss- (Tel4(G)) or ds- (Tel4(GC)) DNA oligonucleotide comprising four telomeric repeats as a probe. "-" - no protein control. Positions of the free DNA and protein/DNA complexes are indicated by arrows. (D) Quantification of the titration EMSA experiment (two replicates) with increasing concentration of recombinant (tag-free) $\operatorname{Rifl}_{\mathrm{NTE}}{ }^{1-264}(0,1,3$, 10, 30, 100, 300, 1000, 3000, $10000 \mathrm{nM}$ ) and $30 \mathrm{nM}$ FAM-Tel4(G) (black circles) or FAM-Tel4(GC) (black squares) as probes (gels are shown in Figure 3 - figure supplement 1A). The fits into the "Specific binding with 233 Hill slope" model are shown in dark red (FAM-Tel4(G) - solid curves; FAM-Tel4(GC) - dashed curves). The 234 best-fit values for Kd apparent and Hill coefficient are shown. (E) Quantification of the competition EMSA 235 experiment (the correspondent gels are shown in Figure 3 - figure supplement 1B) with $30 \mathrm{nM}$ FAM-Tel4(G), 1 $236 \mu \mathrm{M}$ (tag-free) Rif $1_{\mathrm{NTE}}{ }^{1-264}$ and increasing concentration of competitor DNA oligonucleotides $(0.1,0.3,1,3,10,30$ $\mu \mathrm{M})$. The sequences of the competitors are in Table 1. We note that competition with the Tel4(C) oligo may be difficult to interpret since it may first titrate out the FAM-Tel4(G) probe. 
bioRxiv preprint doi: https://doi.org/10.1101/2021.11.07.467630; this version posted November $8,2021$. The copyright holder for this

preprint (which was not certified by peer review) is the author/funder, who has granted bioRxiv a license to display the preprint in perpetuity. It is made available under aCC-BY 4.0 International license.

239 Table 1. Oligonucleotides used in the EMSA experiments.

\begin{tabular}{|l|l|}
\hline Oligo name & Sequence $\left(\mathbf{5}^{\prime} \mathbf{- 3}\right.$ ' $)$ \\
\hline Tel4 (G) & GGGTGGCGGGTGGCGGGGTGGCGGGGTGGCG \\
\hline Tel4 (C) & CGCCACCCCGCCACCCCGCCACCCCGCCACCC \\
\hline Tel4 (GC) & annealed from Tel4 (G) and Tel4 (C) \\
\hline ssrnd1 & ACGACTCACTGTAGATACGACTCACTGTAGAT \\
\hline ssrnd2 & ATCTACAGTGAGTCGTATCTACAGTGAGTCGT \\
\hline ssrnd3 & AAATCTAGACATGAAAAAAAAATGTTAGTAATCGAAATCTC \\
\hline dsrnd1 & annealed from ssrnd1 and ssrnd2 \\
\hline dsrnd2antisense & GAGATTTCGATTACTAACATTTTTTTTTTCATGTCTAGATTT \\
\hline dsrnd2 & annealed from ssrnd3 and dsrnd2antisense \\
\hline
\end{tabular}


Next, we sought to identify residues within the N-terminal extension of HpRifl which are involved in

DNA binding, in order to provide evidence for direct interaction between HpRif1 and telomeric DNA

in living cells. Lack of conservation and intrinsic disorder of Rif1 ${ }_{\mathrm{NTE}}^{1-264}$ precluded us from predicting

DNA-contacting residues by comparison with other known DNA-binding proteins. We tested several

NTE truncation constructs for their ability to shift telomeric DNA in vitro and found amino acids 101-

264 to be dispensable for DNA-binding activity (Figure 4 - figure supplement 1 ). Then we noticed that

region 1-100 of HpRif1 contains two similar clusters enriched in positively charged residues contacts, and we presumed that these two clusters might be responsible for the observed Rif $1_{\mathrm{NTE}}{ }^{1-264}$ -

DNA interaction. We expressed and purified three mutant 6 His-S-Rif $1_{\mathrm{NTE}}^{1-264}$ proteins (Figure 4A, B):

two with four alanine substitutions in either cluster 1 or cluster $2\left({ }^{38} \mathrm{AANNASA}^{44}\right.$ or $4 \mathrm{~A}^{1}$,

${ }^{79}$ AASTNNASA ${ }^{87}$ or $\left.4 \mathrm{~A}^{2}\right)$ and one with eight alanine substitutions $\left({ }^{38} \mathrm{AANNASA}^{44} /{ }^{79} \mathrm{AASTNNASA}{ }^{87}\right.$

or $8 \mathrm{~A}$ ). According to the results of the EMSA experiments, $8 \mathrm{ARif}_{\mathrm{NTE}}{ }^{1-264}$ retained little (if any) ability

to bind DNA in vitro (Figure 4C). Thus, we conclude that regions 38-44 and 79-87 are crucial elements

Then effect of the mutations in N-terminal extension of HpRif1 on its telomeric functions in vivo was tested. Even four alanine substitutions (in either motif) reduce HpRif1 association with telomere VII to the background levels (Figure 4D), while having little effect on the protein abundance (Figure 4E). Telomeres in all three mutant strains were elongated, and comparable to the Rif1 ${ }^{\Delta \mathrm{NTE}}$ strain (Figure $4 \mathrm{~F}$ ).

261 Collectively, these data demonstrate an important role of regions 38-44 and 79-87 for HpRif1 function and argue that DNA-binding activity of the N-terminal extension helps to recruit HpRif1 to telomeres. ScRifl binds DNA in vitro via its crook-shaped structural NTD, however we did not observe DNA binding activity of the HpRif1 fragments corresponding to this region of the protein (Figure 3). This may be explained by the difficulties to correctly fold large protein fragments in a heterologous system, and we tried to find whether DNA-contacting residues from ScRif1 NTD are conserved in HpRif1. 
268 the DNA backbone (Mattarocci et al., 2017). Of these 19, only four are conserved in H. polymorpha

269 Rifl (Figure 4 - figure supplement 2A, Supplementary file 1). Double mutant HpRif1 $1_{\mathrm{K} 658 \mathrm{E} / \mathrm{K} 666 \mathrm{E}}$ is 270 expressed at considerably lower levels than WT HpRif1, indicating that residues K658 and K666 are 271 important for protein stability (Figure 4 - figure supplement 2B). Substitution of the other two conserved 272 amino acids (K504 and R539) for glutamines does not lead to detectable changes in Rif1 telomere 273 occupancy or telomere length (Figure 4 - figure supplement 2C, D). Thus, HpRif1 may lack the DNA274 binding mode described for ScRif1 or it utilizes different amino acids for such interaction. 
$\mathbf{A}$

\begin{tabular}{|c|c|c|}
\hline WT & $\begin{array}{c}\text { cluster \#1 } \\
{ }^{38} \text { KRNNRSR }^{44}\end{array}$ & $\begin{array}{c}\text { cluster \#2 } \\
{ }^{79} \text { KRSTNNKNK }^{87}\end{array}$ \\
\hline $4 A^{1}$ & ${ }^{38}$ AANNASA ${ }^{44}$ & ${ }^{79} \mathrm{KRSTNNKNK}^{87}$ \\
\hline $4 A^{2}$ & ${ }^{38} \mathrm{KRNNRSR}^{44}$ & ${ }^{79}$ AASTNNANA ${ }^{87}$ \\
\hline $8 \mathrm{~A}$ & ${ }^{38}$ AANNASA 44 & ${ }^{79}$ AASTNNANA ${ }^{87}$ \\
\hline
\end{tabular}
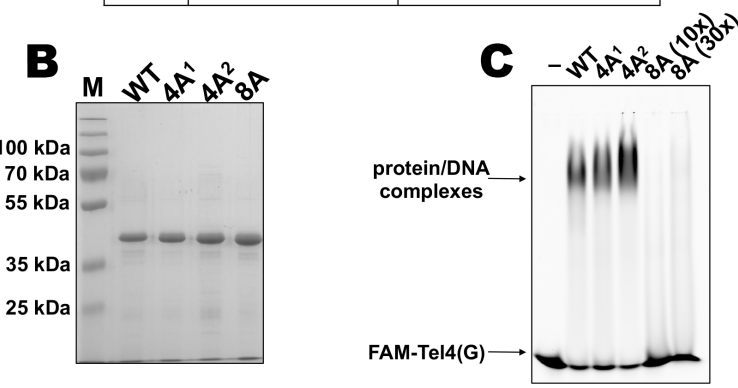

Figure 4. Two K/R clusters within Rif1 are important for its telomeric localization. (A) Sequences of the two clusters enriched in positively charged residues in the wild type and mutant versions of HpRif1. (B) Aliquots of the Ni- NTA purified wild type ("WT") and mutant 1-264 fragments of HpRif1 were analyzed by SDS-PAGE and Coomassie staining. "M" - protein weight marker. (C) $10 \mu \mathrm{M}$ of the indicated 6 His-S-tagged proteins were subjected to EMSA, using $1 \mu \mathrm{M}$ of ss- oligonucleotide comprising four telomeric repeats (FAM-Tel4(G)) as a probe. "-" - no protein control. "30x" $-30 \mu \mathrm{M}$ of the $8 \mathrm{~A}$ mutant protein. Positions of the free DNA and protein/DNA complexes are indicated by arrows. (D) ChIP analysis of the indicated strains, same as in Figure 1D; the \% of input of the "TEL" Rif1*-HA WT sample was set to 1 . Error bars indicate SD, $n=3$. (E) Western blot analysis of the total proteins isolated from the indicated strains using antibodies targeting HA epitope (upper panel). Ponceau S-stained membrane (lower panel) served as a loading control. (F) Southern blot analysis as in Figure 1B but with different strains. 


\section{Rif1 telomere localization depends on the Ku heterodimer}

288 To further investigate the mechanism of Rif1 recruitment, we sought to identify protein-protein 289 interactions in which Rifl may be involved at $H$. polymorpha telomeres. Rif1 and several other telomeric proteins were tested in yeast-two-hybrid (Y2H) assay, which revealed two Rif1-interacting partners: Ku80 and Stn1 (Figure 5A). Interestingly, the interaction with Ku80 (but not with Stn1) appears to be mediated through the Rif1 $1_{\mathrm{NTE}}^{1-264}$ fragment, according to the $\mathrm{Y} 2 \mathrm{H}$ analysis (Figure $5 \mathrm{~A}$ ). By testing several deletion constructs of the $\operatorname{Rifl}_{\mathrm{NTE}}{ }^{1-264}$, we found that the residues required for Ku 80 binding are 294 localized within the 220-240 region of Rif1 (hereafter referred to as Rif1 Ku80-binding motif, or Rifl $_{\mathrm{KBM}}$ ) (Figure 5 - figure supplement 1). This region is fairly conserved in five species closely related to H. polymorpha (Figure 5B, Supplementary file 2), and substitution of either F225 or R230 with a negatively charged glutamic acid residue abolish the Rif $1_{\mathrm{NTE}}{ }^{150-264}-\mathrm{Ku} 80$ interaction in the $\mathrm{Y} 2 \mathrm{H}$ system

298 (Figure 5C).

299 Rif1-Ku interaction can also be observed in vivo by Co-IP experiments (Figure 5D). Deletion of either $K U 80$ or $K U 70$ led to a $\sim 4$-fold reduction in Rif1-HA telomere occupancy (Figure 5E), consistent with the idea that binding to $\mathrm{Ku}$ is important for Rif1 telomere association. In agreement with the Y2H data, Rifl $_{\mathrm{NTE}}{ }^{1-264}$ fragments with either F225E or R230E mutation were unable to localize to telomeres (Figure 5F, G), confirming that Rif1 $1_{\mathrm{NTE}}-\mathrm{Ku} 80$ interaction does occur in vivo. However, F225E and R230E substitutions did not affect the ability of the full-length Rif1 to bind telomeric DNA (Figure 5H). Double mutation F225E/R230E and substitution of amino acids 225-230 with alanines (the $6 \mathrm{~A}$ mutant) also did not perturb Rif1 telomere binding (Figure 5H). Moreover, neither mutation led to a noticeable telomere length increase (Figure 5I). Thus, Rif1 contains other sites for Ku binding which are more important in vivo than $\mathrm{Rif1}_{\mathrm{NTE}}-\mathrm{Ku} 80$ interaction.

309 The idea that Rif1 is recruited at telomeres by $\mathrm{Ku}$ relies on the assumption that Ku itself binds telomeric DNA. To verify this, we performed ChIP experiments with the Ku70-HA and Ku80-HA strains, which

311 showed that telomeric DNA is co-immunoprecipitated with $\mathrm{Ku}$ (Figure 5 - figure supplement 2A). 312 Moreover, deletion of either $\mathrm{Ku}$ component perturbs telomere length maintenance (Figure 5 - figure 
313 supplement $2 \mathrm{~B}$ ), confirming that $\mathrm{Ku}$ heterodimer is indeed a part of telomeric chromatin in $H$.

314 polymorpha. Deletion of RIF1 leads to only 2 -fold reduction in Ku80 occupancy (Figure 5 - figure

315 supplement 2C), in agreement with the idea that Rif1 is more reliant on the Ku's presence at telomeres

316 than $\mathrm{Ku}$ on Rifl's. However, Ku loss leads to telomere shortening ( $25-50 \%$ reduction in telomere

317 length, Figure 5 - figure supplement 2B, Figure 5J), indicating to a positive role of $\mathrm{Ku}$ in telomere

318 lengthening. To verify that Rif1 telomere localization defect upon $\mathrm{Ku}$ loss is not simply a consequence

319 of the telomere shortening, we measured Rif1 telomere binding in a strain lacking telomerase RNA

320 (Figure 5 - figure supplement 2D, E). TER knock-out resulted in $\sim 40 \%$ reduction in telomere length,

321 whereas Rif1-HA telomere occupancy diminished only 2-fold (Figure 5 - figure supplement 2D, E);

322 contrasting to $\sim 4$-fold Rif1 ChIP signal drop in case of $\mathrm{Ku}$ mutants (Figure 5E).

323 Interestingly, RIF1 deletion in a $\Delta k u 80$ background does not lead to strong telomere elongation 324 compared to the parental $\Delta k u 80$ strain, suggesting that inhibition of telomerase by Rifl is attenuated in 325 the absence of $\mathrm{Ku}$ (Figure 5J). Moreover, inhibition by the Rif1 ${ }_{\mathrm{NTE}}{ }^{1-264}$ fragment is lost completely: no telomere lengthening is observed in the Rif ${ }^{\Delta \mathrm{NTE}} \Delta k u 80$ strain compared to the $\Delta k u 80$ strain (Figure $5 \mathrm{~J}$ ).

327 These results suggest that $\mathrm{Ku}$ potentially recruits some telomere addition factor, while the Rif1 fragment 328 may compete with this putative factor for $\mathrm{Ku} 80$ binding. In $S$. cerevisiae, $\mathrm{Ku}$ is one of the accessory 329 subunits of telomerase stably bound to its RNA component. We found that HpTER cannot be efficiently 330 co-purified with Ku80-HA, while it robustly binds TERT-HA, Est1-HA and Est3-HA in the same 331 experimental conditions (Figure 5 - figure supplement 2F, (Shepelev et al., 2020)), suggesting that $332 \mathrm{HpKu}$ is not a stable telomerase component. This does not exclude, however, the possibility of weak or 333 transient association between Ku and telomerase in H. polymorpha. Consistent with this idea, we observe 334 weak but noticeable interaction between HpTERT and HpKu80 in the Y2H assay ((Figure 5 - figure 335 supplement 2G). 


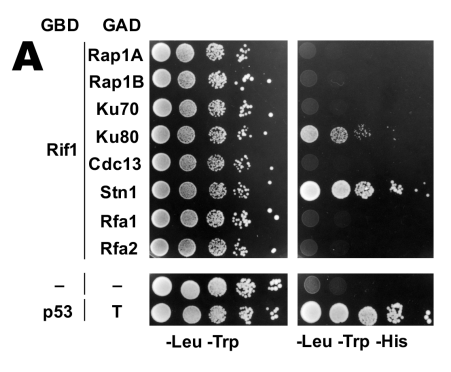

B

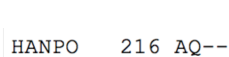

OGAPO

OGARH

OGAMI

OGANON

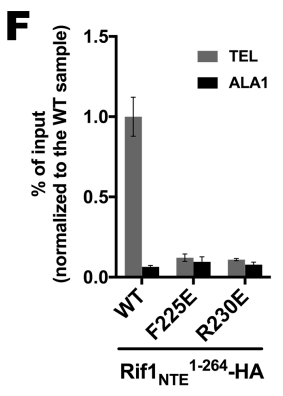

G

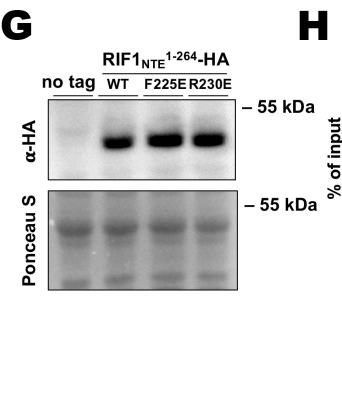

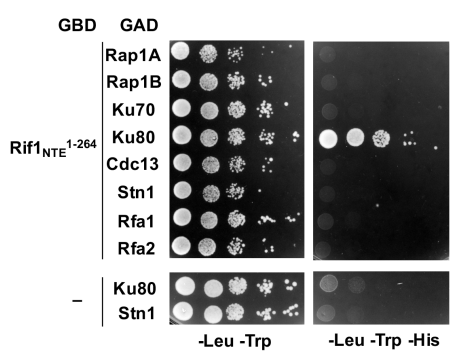
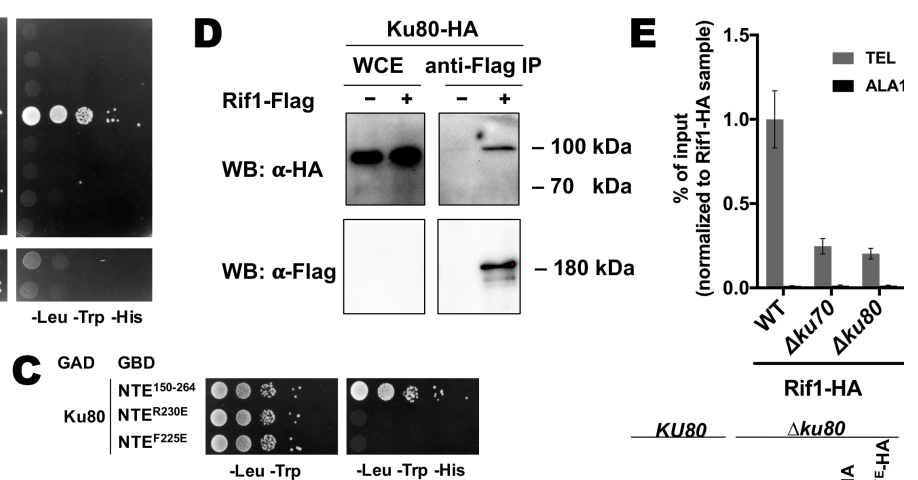

Rif1*-HA

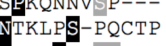

NTEF 225

1
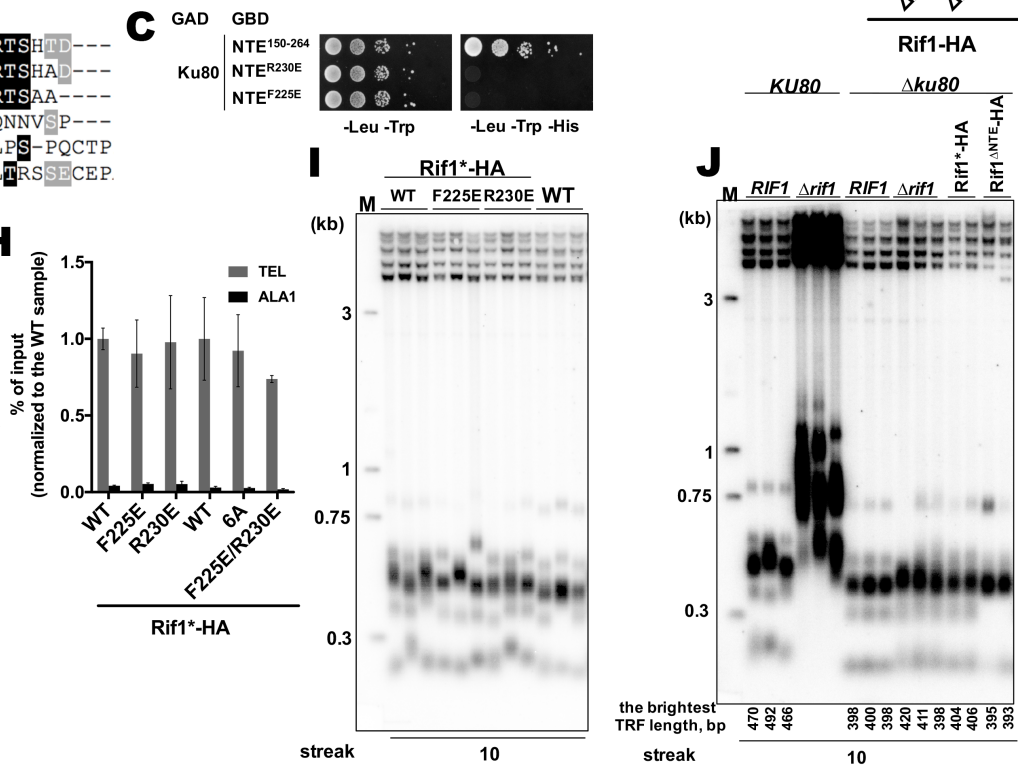

Figure 5. Rif1 interacts with Ku80 in H. polymoprha (A) Y2H analysis. AH109 colonies expressing pairs of the indicated proteins (fused to either Gal4-BD (GBD) or Gal4-AD (GAD)); cultures with $\mathrm{A}_{600} \sim 0.5$ and four 10-fold serial dilutions were plated on the SC medium lacking amino acids as indicated, and incubated at $30{ }^{\circ} \mathrm{C}$ for four days. "T" - SV40 large T antigen. (B) A fragment of the alignment of the NTE regions from H. polymoprha DL1 (HANPO) and five of its closest relatives. Full alignment is in Supplemental file 2. (C) Y2H analysis as in (A), “NTE ${ }^{\mathrm{R} 230 \mathrm{E} \text { ” and "NTE }}{ }^{\mathrm{F} 225 \mathrm{E}, ~-~ 150-264 ~ f r a g m e n t s ~ o f ~ R i f 1 ~ w i t h ~ t h e ~ R 230 E ~ a n d ~ F 225 E ~ m u t a t i o n s, ~ r e s p e c t i v e l y . ~}$

Co-IP analysis. IP on the anti-Flag resin. The amount of tagged proteins in whole cell extracts (WCE) and the IP samples (IP) was monitored by Western blot (WB) using anti-Flag and anti-HA antibodies. The IP experiment was performed in the presence of benzonase nuclease. (E, F) ChIP analysis of the indicated strains, same as in Figure 1D; the \% of input of the "TEL" Rif1-HA WT sample was set to 1 (E); the \% of input of the "TEL" Rif $_{\mathrm{NTE}}^{1-264}$-HA WT sample was set to $1(\mathrm{~F})$. (G) Western blot analysis. Same as in Figure 1F, but with different strains. $(\mathrm{H})$ ChIP analysis of the indicated strains, same as in Figure 1D; Error bars indicate SD, $\mathrm{n}=3$. "6A" mutation: ${ }^{225} \mathrm{FQAVVR}^{230} / 225 \mathrm{AAAAAA}^{230}$. (I, J) Southern blot analysis as in Figure 1B (J) Mean lengths of the brightest TFR bands are: RIF1KU80 476 bp, RIF1 kku80 399 bp. WT telomere length reported to be $\sim 160$ bp ( 20 telomeric repeats, (Sohn et al., 1999)), therefore telomere length is reduced by $\sim 50 \%$ in the knockout strain. 


\section{Rif1 is important for recruitment of Stn1 protein to telomeres}

353 Next, we decided to study telomeric role of the interaction between Rif1 and Stn1. First, we confirmed

354 the ability of the proteins to form a complex in vivo by the Co-IP experiment. Stn1-HA co-elutes with 355 Rif1-HA following immunoprecipitation on the anti-Flag resin (Figure 6A). Benzonase treatment of the extracts prior to the IP does not diminish the amount of co-precipitated Stn1 (Figure 6A), suggesting that the Rif1-Stn1 interaction is DNA-independent. We were unable to test the effect of the STN1 358 knockout on the Rif1 telomere binding, since Stn1 is essential for cell viability (as two other components 359 of the CST complex - Cdc13 and Ten1, Figure 6 - figure supplement 1A). However, we found that 360 removal of either N- or C-terminal Stn1 domains is sufficient to completely disrupt binding to Rif1 in 361 the Y2H assay (Figure 6B, C). C-terminal truncations in Stn1 are well tolerated by cells, although the 362 Stn $1^{\Delta \mathrm{C} 381}$-Flag and $\mathrm{Stn} 1^{\Delta \mathrm{C} 221}$-Flag strains have greatly elongated telomeres (Figure 6D), similar to the 363 Stn1 truncation mutants in S. cerevisiae (Petreaca et al., 2007, 2006; Puglisi et al., 2008). Rif1 telomere 364 association is reduced in the strains with these $\sin 1$ mutations, although the reduction is relatively modest 365 ( 2.5-fold, Figure 6E). Interestingly, we found that Stn1 telomere binding is completely abolished upon 366 RIF1 deletion, suggesting that it is actually Rif1 that recruits Stn1 to telomeres, and not vice versa 367 (Figure 6F). Stn1 telomere occupancy is also diminished ( 2-fold) in the $\Delta k u 80$ strain, which has smaller 368 amount of the telomere-bound Rif1 (Figure 6F). Finally, we found that Rif1 bind Stn1 in Y2H through 369 its conserved NTD, more precisely - the 265-897 region (Figure 6G). 

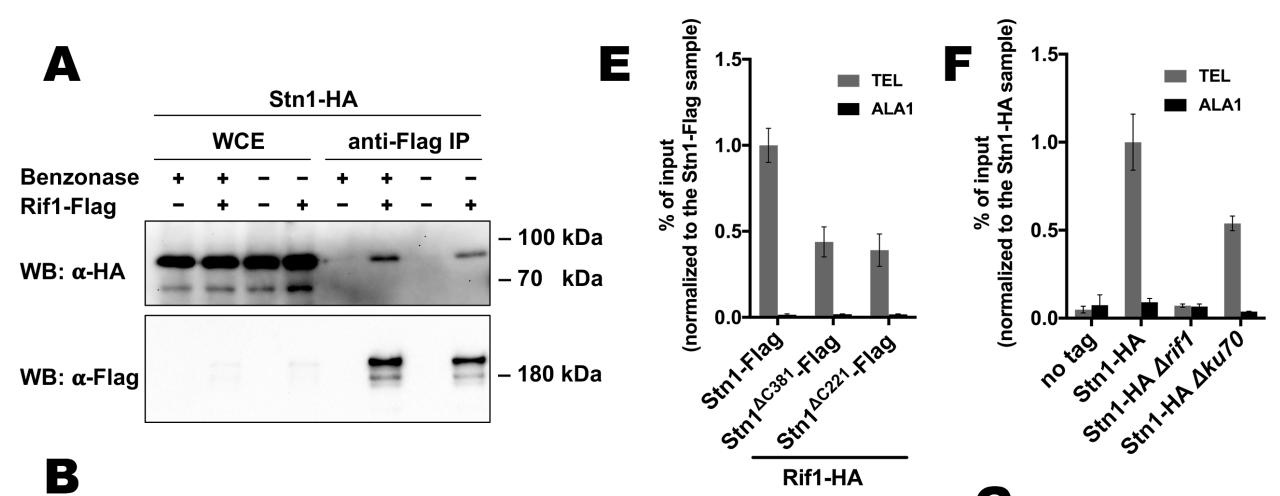

B

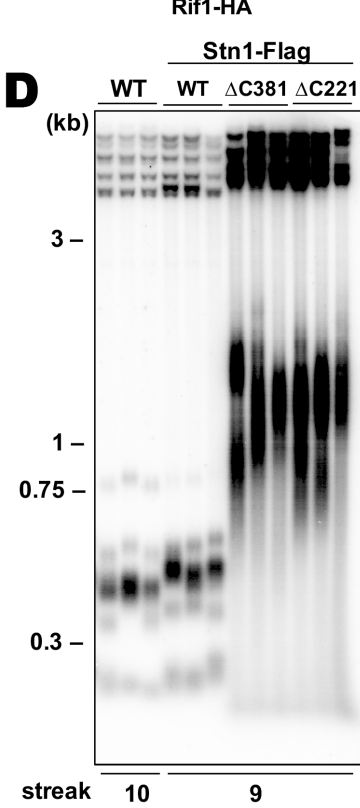

$\mathbf{G}$
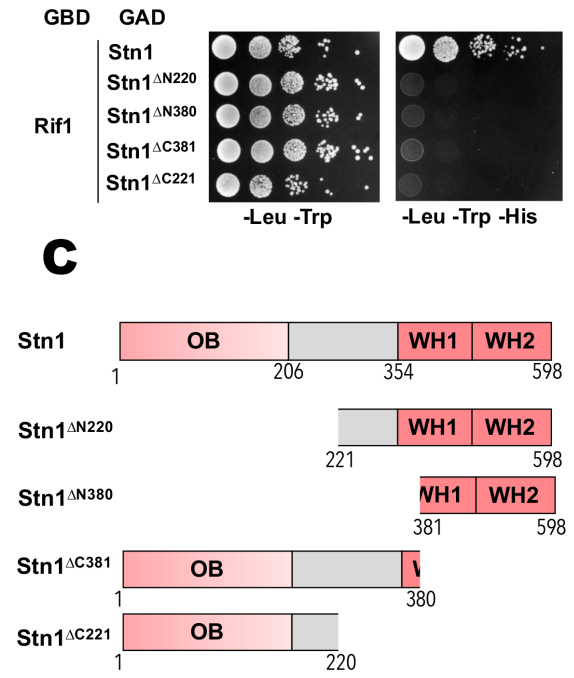

371 Figure 6. Rif1 recruits Stn1 at H. polymorpha telomeres. (A) Co-IP analysis. Same as in Figure 5I, but with

372 different strains; the IP experiment was performed either with or without benzonase treatment as indicated. (B)

$373 \mathrm{Y} 2 \mathrm{H}$ analysis. Same as in in Figure 5A, but with different protein pairs. (C) Schematic illustration of the domain 374 organization of the full length HpStn1 and its truncation variants used in this study. (D) Southern blot analysis as 375 in Figure 1B but with different strains. (E, F) ChIP analysis of the indicated strains, same as in Figure 1D (IP on 376 the anti-HA beads); the \% of input of the "TEL" Rif1-HA/Stn1-Flag sample was set to 1. Error bars indicate SD, $377 n=3$. (E) or the \% of input of the "TEL" Stn1-HA sample was set to 1 (F). (G) Y2H analysis. Same as in in Figure 378 5A, but with different protein pairs. 


\section{DISCUSSION}

We found that Rifl from the methylotrophic yeast $H$. polymorpha prevents hyperelongation of telomeres, similar to its other yeast counterparts. In S. cerevisiae, Rif1's function strongly depends on the recruitment by Rap1 protein (specifically, by the Rap1 ${ }^{\text {RCT }}$ domain). Hence, telomerase-dependent telomere overelongation can be observed in the strains with either deletion of the RIF1 gene, or mutations that disrupt Rap1-telomere association (Hardy et al., 1992; Shi et al., 2013; Teng et al., 2000).

Long telomeres in the $\Delta$ rifl strain of $H$. polymorpha do appear to be solely maintained by telomerase

(Figure 1B, C). H. polymorpha has two Rap1 paralogues, however, HpRap1A does not recognize telomeric DNA and RCT removal from Rap1A has no effect on telomere length (Malyavko et al., 2019). HpRap1B associates with double-stranded telomeric DNA and the 50 a.a. C-terminal truncation (Rap1B $^{1-526}$ ) leads to more than 10-fold drop in Rap1B expression and strong telomere elongation. In contrast to the $\Delta$ rifl strain, longer telomeres in this $\mathrm{B}^{1-526}$ strain were found to depend primarily on recombination (Malyavko et al., 2019). This phenotypic discrepancy indicates that functions of Rap1 and Rif1 in H. polymorpha may not be as intimately linked as in S. cerevisiae. In addition, we could not identify the Rap1-binding motif within HpRif1. We failed to detect a direct interaction between HpRif1 and either of the two HpRap1 paralogues in the $\mathrm{Y} 2 \mathrm{H}$ experiment (Figure 5A). Finally, Rap1B can efficiently localize to internal as well as terminal telomeric dsDNA (as expected from a sequence specific telomeric factor), whereas Rif1 has a clear preference for telomeric repeats located at the end of the chromosome (Figure 1 - figure supplement 1). Thus, although we cannot exclude the possibility of an interaction between HpRap1 and HpRifl, we believe that it is highly unlikely that Rif1 binding to Rap1 400 is the major mechanism of Rif1 telomeric recruitment in H. polymorpha in a manner it is described for 401 its $S$. cerevisiae homologues.

Rifl homologues from many species contain a DBD, and DNA binding by the NTD of $S$. cerevisiae 
us to test whether HpRifl might be recruited at telomeres by means of direct interaction with telomeric DNA. We found that HpRif1 fragments containing amino acids 1-264 possess DNA-binding activity in vitro. The Rif $1_{\mathrm{NTE}}^{1-264}$ fragment can be detected at telomeres by ChIP, while its removal (the Rif1 ${ }^{\Delta \mathrm{NTE}}$ strain) strongly diminishes the telomere binding of Rif1. Moreover, mutations that abolish DNA-binding in vitro lead to the substantial (if not complete) loss of HpRif1 from telomeres and telomere elongation comparable to the Rif1 ${ }^{\Delta \mathrm{NTE}}$ strain (Figure 4). These results are in favor of the "recruitment via direct telomeric DNA binding" hypothesis. The identified DNA-binding mode by the intrinsically disordered portion of HpRif1, however, is clearly different from the one utilized by the conserved structured NTD of ScRif1. We could not detect a DNA binding activity of the HpRifl ${ }_{\mathrm{NTD}}$ (residues $~ 310-1000$, Figure 3A-C), although this may be due to improper folding of the large polypeptides in the E. coli expression system or suboptimal conditions of the EMSA reactions. Despite the fact that the NTD is a relatively well conserved region of Rifl, we found that of 19 charged amino acids constituting the DBD of ScRif1 only 4 can be found in HpRif1 and their mutation has no apparent effect on Rif1-telomere association (Figure 4 - figure supplement 2). Given the high evolvability of telomeric proteins, we do not, however, dismiss the possibility that HpRif1 may contact DNA through different amino acids within its NTD domain.

Interestingly, there is a discrepancy between our ChIP experiments, which suggest that Rif $1_{\mathrm{NTE}}$ is necessary and sufficient for the telomeric localization of Rifl, and the telomere length analysis, which points to the relatively minor contribution of the Rifl $1_{\mathrm{NTE}}$ to the telomere length control (Figure 4D, F). This points to the existence of another mode(s) of HpRif1 recruitment, which may evade detection by ChIP, perhaps, because it is restricted to the short window of the cell cycle or due to its transient nature. This second mode could be attributed to the DNA binding by the NTD (similar to the ScRif1) and/or to the interaction of HpRif1 with another telomeric protein.

Our search for Rifl's protein partners at telomeres revealed two hits - Ku80 and Stn1 - and deletion of the $K U 80$ gene does lead to strong reduction in Rif1 telomere occupancy, suggesting that this interaction plays an important role in localizing Rif1 to telomeres (Figure 5). Although in the Y2H assay the Ku80- 
Rif1 interaction depends primarily on the short motif within Rif1 $1_{\mathrm{NTE}}$, our experiments indicate that in $H$. polymorpha cells the robust Ku80-Rif1 association requires other Rif1 domains. The Rif1 $1_{\mathrm{KBM}}$ may thus serve only as an auxiliary module, which is consistent with the fact that it is conserved only in five species closest to H. polymorpha. The interaction of NTE-less Rif1 with Ku could therefore represent the second mode of telomeric recruitment of HpRif1 responsible for the telomerase inhibition in the $\operatorname{Rif1}^{\Delta \mathrm{NTE}}$ strain.

In $S$. cerevisiae, telomere tract length determines the probability of the elongation of a chromosomal end: shorter telomeres are preferred substrates for telomerase (Marcand, 1999; Teixeira et al., 2004). At the basis of this regulation is "counting" of telomeric repeats by Rap1 that defines the number of (telomerase-inhibitory) Rif1 and Rif2 molecules present at any given telomere (Levy and Blackburn, 2004; Marcand et al., 1997). H. polymorpha lacks Rif2 entirely, and at this point it is not obvious how mechanistically Rif1 recruitment could be linked to telomere length. In fact, HpRif1 appears to have only limited ability to bind double-stranded telomeric DNA in vivo (Figure 1 - figure supplement 1). It should be noted, that Rif1 is a large protein with many functions and, even in S. cerevisiae, it is not fully involved in the "counting" process. The Rif1 ${ }^{\mathrm{RBM}}$ mutant lacking the ability to contact Rap1 is almost completely lost from telomeres as judged by ChIP, yet retains a significant portion of its telomerase inhibitory potential (Mattarocci et al., 2017; Shi et al., 2013). Thus, budding yeast Rif1 homologues may operate (at least partially) in a telomere length-independent way.

Similarly to S. cerevisiae (Boulton, 1996; Porter et al., 1996), deletion of the subunits of the HpKu heterodimer leads to pronounced telomere shortening (Figure 5 - figure supplement $1 \mathrm{~B}$ ). ScKu recognizes a specific stem-loop structure within telomerase RNA, mediating one of the two pathways of telomerase recruitment (Chen et al., 2018; Peterson et al., 2001; Stellwagen, 2003). Our previous analysis of the $H$. polymorpha telomerase RNA structure did not reveal a similar Ku-binding hairpin 454 (Smekalova et al., 2013) and the lack of a stable interaction between Ku and HpTER was confirmed experimentally in this study (Figure 5 - figure supplement 2F). Shorter telomeres in the HpKu knockout strains could be explained, however, by a transient association with telomerase via another 
telomerase subunit (for example like in human cells, where an interaction between Ku and TERT has been detected (Chai et al., 2002)). Indeed, we found that HpTERT binds HpKu80 in the Y2H experiment (Figure 5 - figure supplement 2G). Interestingly, we observed only minor telomere elongation upon HpRif1 loss in the $\Delta k u 80$ background, suggesting that Rif1 counteracts the positive effect of the Ku at telomeres (Figure 5J). We propose that Rifl's inhibitory function in H. polymorpha may involve a direct competition with telomerase for Ku binding at telomeres (Figure 6 - figure supplement 2).

The second pathway of telomerase recruitment in $S$. cerevisiae relies on the binding of the Est1 telomerase subunit to the RD (recruitment domain) of the Cdc13 protein (Chen et al., 2018; Evans and Lundblad, 1999; Pennock et al., 2001). Association with Stn1 blocks this interaction, thereby limiting the amount of telomerase at telomeres (Chandra, 2001; Li et al., 2009; Pennock et al., 2001). Although HpCdc13 is shorter than ScCdc13 and lacks the RD domain (and, apparently, the ability to bind Est1), we have demonstrated recently, that it can bind both telomerase (via the TERT subunit) and Stn1 in a $\mathrm{Y} 2 \mathrm{H}$ assay, indicating that a similar mechanism of telomerase regulation may be operating in $H$. polymorpha (Malyavko and Dontsova, 2020). Alternatively, Stn1 may influence telomerase binding indirectly, by controlling the amount of ssDNA (and therefore Cdc13, which is a ssDNA binding protein) at telomeres (Grandin et al., 1997). In any case, we found that Stn1 accumulation at telomeres depends strongly on Rif1, and that mutations disrupting Stn1-Rif1 (and Stn1-Cdc13) interaction lead to highly elongated telomeres (Figure 6). Thus, we speculate that the negative effect of Rif1 on telomere length may also be explained by its ability to promote Stn1 telomere localization, thereby attenuating the telomerase recruitment via Cdc13 (Figure 6 - figure supplement 2).

Remarkably, the existence of a physical interaction between Rifl and the CST complex was proposed (but not demonstrated experimentally) in a study by Anbalagan et al (Anbalagan et al., 2011) to explain the specific requirement of Rif1 for viability of $S$. cerevisiae cells with hypomorphic mutations in Cdc13 and Stn1. Our Y2H experiments show that Stn1 binds the NTD of Rif1 (Figure 6G). Rif1 $1_{\mathrm{NTD}}$ contains the most conserved portion of the protein (Supplementary file 1) that is present in all Rifl orthologues 
(Mattarocci et al., 2017; Sreesankar et al., 2012). Hence it is plausible that the Stn1-Rif1 direct 483 interaction observed in our study may be present in other species.

484 In summary, in the present study we have identified several novel aspects of Rif1 function in budding yeasts. We demonstrated that the N-terminal extension (NTE) of Rifl is an accessory domain partially promoting Rif1 telomeric localization in H. polymorpha. Given that DNA binding by Rif1 $1_{\mathrm{NTE}}$ is weak and lacks clearly defined specificity towards a particular telomeric substrate, we believe that it may 488 simply stabilize Rif1 at telomeres, while the preference for the telomeric chromatin is provided by the 489 ability to contact Ku heterodimer. Consistently, Rif1 ${ }_{\mathrm{NTE}}^{1-264(\mathrm{~F} 225 \mathrm{E})}$ and Rif1 ${ }_{\mathrm{NTE}}^{1-264(\mathrm{R} 230 \mathrm{E})}$ mutants (unable 490 to bind $\mathrm{Ku} 80$, but with intact DBD) fail to localize to telomeres (Figure 5G). Our results also indirectly 491 point to the possibility of the DNA recognition by the HpRifl $1_{\mathrm{NTD}}$ in a manner akin to ScRif1, which 492 recognizes the 3 '-overhang containing ss-ds junctions (Mattarocci et al., 2017). This may also be a factor 493 driving HpRif1 to the chromosomal ends. Finally, we uncovered a HpRif1's role in loading Stn1 protein 494 onto telomeres. Curiously, the mammalian Rif1 homologue is important for the recruitment of CST 495 complex to promote NHEJ at several types of DSBs (although the Rif1-CST interaction is not direct, 496 but mediated via the Shieldin complex) (Barazas et al., 2018; Chapman et al., 2013; Dev et al., 2018; Di 497 Virgilio et al., 2013; Escribano-Díaz et al., 2013; Gupta et al., 2018; Mirman et al., 2018; Noordermeer 498 et al., 2018; Tomida et al., 2018; Zimmermann et al., 2013). It is tempting to speculate that Rifl's role 499 in recruiting Stn1 may be conserved from yeasts to human. 


\section{MATERIALS AND METHODS}

\section{Yeast strains and constructs}

503 The strains used in this study are listed in Supplemental Table S1. The DL1-L strain (Kang et al., 2005) 504 was used as a wild type (no tag) control in all experiments. Gene replacements (detailed below) and random spore analysis was performed as described (Malyavko et al., 2019). The gene replacements were verified by PCR, mutagenesis was verified by sequencing.

1-1001 bp region of the RAD52 gene, 190-480 bp region of the HpTER gene and 196-2076 bp region of the KU80 gene were replaced with pKAM555 plasmid (linearized with SmaI) (Agaphonov et al., 2009). For the HpRIF1 knockout, -33-4430 bp region of the RIF1 gene was replaced with HpLEU2 gene from pCHLX vector (Sohn et al., 1996). For the HpKU70 knockout, 214-1698 bp region of the KU70 gene was replaced with either HpLEU2 gene from pCHLX, or pKAM555 (linearized with SmaI).

512 For C-terminal 3HA tagging, stop codon (or a relevant portion of the gene, in case of a concomitant C513 terminal truncation) was replaced with SmaI-PmeI fragment of the pFA6a-3HA-HpURA3 plasmid 514 (Malyavko et al., 2019). The pFA6a-Rif1-3HA-HpLEU2 vector was constructed by replacing the BglII/PmeI fragment of the pFA6a-Rif1-3HA-HpURA3 with the HpLEU2 marker gene (generated by PCR from the pCHLX vector with primers F: 5'-aaaagatctccaccgcggtggc-3' and R: 5'517 cgggggatcctactttttttctcc-3'); then the 3HA sequence was replaced with 3Flag by PCR and self-ligation of the pFA6a-Rif1-3HA-HpLEU2 (primers

F: 5'caccgtcatggtctttgtagtctccaccccgectccccgegtcttttttcaaacacgtc-3'

and $\mathrm{R}$ : 5'attataaagatcatgacatcgactacaaggatgacgatgacaagtagggcgcgccacttctaaataag-3'), generating the pFA6aRif1-3Flag-HpLEU2 vector. For C-terminal 3Flag tagging, stop codon (or a relevant portion of the gene, in case of a concomitant C-terminal truncation) was replaced with the 3FlagLEU2 fragment (primers F:

523 5'-gggggaggcgggggtggagactac-3' and R: 5'-cgggggatcctactttttttctcc-3') of the pFA6a-Rif1-3FlagHpLEU2. 
For mutagenesis of the NTE of HpRif1 we generated the p5rCHLXpr plasmid by cloning upstream RIF1

flanking region (primers

F: 5'-aacce aaatctagacgggtgtgtgattctgcaaacc-3')

and RIF1 promoter

(primers

F: 5'aaggatccaaaaaccaaaaaaaatgccagcttgaaaaaaattg-3';

R: 5'-aagaattcggcttctggttggaaaatacag-3') at $\mathrm{SacII} / \mathrm{XbaI}$ sites and BamHI/EcoRI sites, respectively, of the pCHLX vector. Then RIF1 fragments (F: 5'-aaagatatcatgagtgctaatgacaacgacacg-3'; R: 5'-aaagtcgacaggcggactcactttcaagattg-3') and (F: 5'aaagatatcatgcgggacgcggccggcaac-3' R: 5'-aaagtcgactccacggcgtgcaagctca-3') were cloned at 533 SalI/EcoRV sites to generate templates for Rif1*-HA and Rif1 ${ }^{\Delta \mathrm{NTE}}-\mathrm{HA}$ cassettes, respectively. 534 Templates for integration cassettes with mutations in NTE were introduced by PCR amplification of the plasmid with the template for Rif1*-HA cassette and subsequent self-ligation. All resulting cassettes were PCR amplified and transformed into Rif1-HA strain to generate Rif1*-HA, Rif1 ${ }^{\Delta \mathrm{NTE}}$-HA and the mutant Rif1*-HA strains.

In the heterozygous $H$. polymorpha CBS4732 strains the portions of the genes (-17-951 bp of CDC13; 22-1618 bp of STN1; 1-365 bp of TEN1; 78-1582 bp of KU70) were replaced with HpLEU2 gene from pCHLX.

For the intTEL18 strain creation we generated the pUC19LGPH36 plasmid by cloning leu2 gene (from DL1-L genome) with flanking regions (primers F: 5'-gcgcgtgtctcagcatgaac-3'; R: 5'543 ggtgtgggaggtagaagagg-3') at the pUC19 SmaI site. The leu2 ORF was replaced (primers F: 5'544 aaaaagatctaattatactgttgcgcgaagtagtcccatggtaggatctcgaataattcctaaataatcc-3';

R: $5^{\prime}-$ gattgcaaaatgatggaactattttgc-3') by the PstI(blunted)-BclI fragment of the HARS36 sequence (Sohn et al., 1999) from the AMIpSL1 vector (Agaphonov et al., 1999). Then the G418 ${ }^{\mathrm{R}}$ gene (primers F: 5'aaaaaagacaggaatgagtaaatgaagatcctttgatcttttctacgg-3';

$\mathrm{R}:$ 5'548 ccgggaaaaactgaaaaaccattggcacgacaggtttccegac-3' from the pKAM555 vector) was inserted at the ClaI 549 site using HiFi assembly (NEB). For the intTEL0 strain creation the pUC19LG plasmid (lacking the PstI(blunted)-BclI fragment of the HARS36 sequence) was used. 


\section{Yeast growth conditions}

553 Normally, single colonies from the transformation plates were restreaked on YPD plates and grown for

5542 days at $37{ }^{\circ} \mathrm{C}$. After 10 restreaks ( 230 cell divisions) cells were grown in $10 \mathrm{ml}$ of YPD at $37^{\circ} \mathrm{C}$ overnight and used for Southern blot analysis.

For the $\Delta$ ter strains viability assay (Figure $1 \mathrm{~B}, \mathrm{C}$ ) several colonies from the transformation plate were resuspended in $100 \mu \mathrm{l}$ of water: $50 \mu \mathrm{l}$ were used for yeast colony PCR, $2 \mu 1$ were plated onto a fresh YPD plate and grown for 2 days at $37^{\circ} \mathrm{C}$ (“streak 1" plate), $48 \mu 1$ were added to $10 \mathrm{ml}$ of YPD and grown overnight at $37^{\circ} \mathrm{C}$ (used for gDNA isolation and Southern blot, "streak 0"). Single colonies from the "streak 1" plate were resuspended in $10 \mu 1$ of water, $3 \mu 1$ were plated onto a fresh YPD plate and grown for 2 days at $37^{\circ} \mathrm{C}$ (“streak 2" plate), $7 \mu 1$ were added to $10 \mathrm{ml}$ of YPD and grown overnight at $37{ }^{\circ} \mathrm{C}$ (used for gDNA isolation and Southern blot, "streak 1"). Single colonies from the "streak 2"

563 (smears of colonies in case of the $\Delta$ ter strains) plate were restreaked onto a fresh YPD plate and grown 564 for 2 days at $37^{\circ} \mathrm{C}$ (“streak 3 " plate). The TER strains were restreaked seven additional times, single colonies from the "streak 10" were grown in $10 \mathrm{ml}$ of YPD overnight at $37^{\circ} \mathrm{C}$ and used for Southern blot. Two colonies of each genotype were analyzed in this experiment (biological replicates).

\section{Telomere Southern blots}

569 Southern blot experiments were carried out as previously described (Shepelev et al., 2020). TRF length were calculated using the ImageQuant TL 1D software version 7.0.

\section{Chromatin Immunoprecipitation (ChIP)}

573 ChIP experiments were performed as previously described (Malyavko et al., 2019) with the following 574 modifications. Cells were grown in $100 \mathrm{ml}$ of YPD at $37^{\circ} \mathrm{C}$ and fixed with $1 \%$ formaldehyde for $30 \mathrm{~min}$ at $25^{\circ} \mathrm{C}$. Lysates were incubated with anti-HA magnetic beads for 2 hours. High-salt lysis buffer 
between at least three replicates (cultures from three colonies of the same strain) as a value of the experimental error.

\section{Co-immunoprecipitation (Co-IP) and Western blots}

Co-IP experiments were performed as previously described (Shyian et al., 2020) with the following modifications. $\mathrm{OD}_{600} \sim 0.9$ cell cultures were used to prepare $1 \mathrm{ml}$ of lysate. Cells were broken with glass beads in a Precellys Evolution homogenizer. $20 \mu 1$ of anti-Flag M2 gel (Sigma) per $1 \mathrm{ml}$ of lysate were used. Proteins were eluted by boiling at $95^{\circ} \mathrm{C}$ for $10 \mathrm{~min}$ in $30 \mu \mathrm{l}$ of $2 \mathrm{x}$ SDS-PAGE buffer (100 mM Tris $\mathrm{pH} 8,4 \%$ SDS, $10 \%$ glycerol, $0.2 \%$ bromophenol blue). Total proteins were isolated as previously described(Kushnirov, 2000). Proteins were separated on 8\% PAGE gels, transferred onto Hybond P 0.22 PVDF membrane (GE Healthcare), stained with Ponceau S (Amresco), and blocked in 5\% BSA. AntiHA-HRP antibodies (clone 3F10, Sigma) at 1:5000, anti-FLAG M2 antibodies (Sigma) at 1:5000, goat anti-mouse IgG-HRP (62-6520, Thermo Fisher Scientific) at 1:5000 and SuperSignal ${ }^{\mathrm{TM}}$ West Femto Maximum Sensitivity Substrate (Thermo Fisher Scientific) were used for protein detection.

RNA Co-IP experiments were performed as described in (Shepelev et al., 2020)

\section{Protein Expression and Purification}

Rif1 fragments for EMSA were expressed and purified as HpRap1B protein (Malyavko et al., 2019). For CD and NMR studies 1-264 HpRif1 fragment was purified in $50 \mathrm{mM}$ phosphate buffer, $\mathrm{pH}$ 7.5, 500 $\mathrm{mM} \mathrm{NaCl}, 10 \mathrm{mM} \beta$-ME, 10\% glycerol, 0,05\% Tween 20, 30mM Imidazole, 0,3 mM PMSF followed by ion-exchange chromatography on Heparine agarose (Sigma). Then 6His- and S-tags were excised by overnight incubation with recombinant TEV protease at $4{ }^{\circ} \mathrm{C}$; tags and TEV protease were removed by an additional round of affinity chromatography on Ni-NTA-agarose (Sigma). As a final step gel filtration on a Superdex 75 column in $20 \mathrm{mM}$ phosphate buffer, $\mathrm{pH} 7.5,50 \mathrm{mM} \mathrm{NaCl}, 5 \%$ glycerol was applied. $750 \mu \mathrm{g}$ of ovalbumin, $400 \mu \mathrm{g}$ of carbonic anhydrase and $400 \mu \mathrm{g}$ of lactalbumin were injected separately 
to serve as standards. For the ${ }^{15} \mathrm{~N}$ isotope labeling cells were cultivated at $37{ }^{\circ} \mathrm{C}$ in $\mathrm{M} 9$ minimal medium with $1 \mathrm{~g} / \mathrm{L}^{15} \mathrm{NH}_{4} \mathrm{Cl}$ (Cambridge Isotope Laboratories, Inc.).

\section{Biophysical Measurements}

CD spectra were recorded at the following temperatures: $5,15,25,35$ and $50^{\circ} \mathrm{C}$. A protein concentration of $0.3 \mathrm{mg} / \mathrm{ml}$ was used in $20 \mathrm{mM}$ phosphate buffer, $\mathrm{pH} 7.5,50 \mathrm{mM} \mathrm{NaCl}, 5 \%$ glycerol. $\mathrm{CD}$ measurements were made on a Chirascan CD spectrometer (Applied Photophysics) using a 0.1-mm path length.

The NMR samples with concentration of $0.2 \mathrm{mM}{ }^{15} \mathrm{~N}$-labeled protein were prepared in $90 \% \mathrm{H}_{2} \mathrm{O} / 10 \%$ $\mathrm{D}_{2} \mathrm{O}, 50 \mathrm{mM} \mathrm{NaCl}$, and $20 \mathrm{mM}$ sodium phosphate buffer ( $\mathrm{pH}$ 7.2). Spectra were acquired at $298 \mathrm{~K}$ on a Bruker Avance $600 \mathrm{MHz}$ spectrometer equipped with a triple resonance $\left({ }^{1} \mathrm{H},{ }^{13} \mathrm{C}\right.$ and $\left.{ }^{15} \mathrm{~N}\right)$ pulsed field z gradient probe. NMR spectra were processed and analyzed using the Mnova software (Mestrelab Research, Spain).

\section{Electrophoretic Mobility Shift Assay (EMSA)}

The sequences of the oligonucleotides used in EMSA are in Table 1. EMSA experiments were performed as described (Malyavko et al., 2019) with the following modification. Reaction buffer contained $10 \mathrm{mM}$ HEPES-NaOH, pH 7.5, $100 \mathrm{mM} \mathrm{NaCl}, 0.5 \mathrm{mM}$ DTT, $0.25 \mathrm{mg} / \mathrm{ml}$ bovine serum albumin, 5\% glycerol. Band intensities (BI) were quantified in ImageQuant TL 7.0, values of "fraction DNA bound" (FDB) were calculated using formula $\mathrm{FDB}=\mathrm{BI} *($ complex $) /(\mathrm{BI} *($ complex $)+\mathrm{BI}($ free $\mathrm{DNA}))$, where $\mathrm{BI}$ (complex) is $\mathrm{BI}$ of the complex minus $\mathrm{BI}$ of the corresponding area in the "no protein control" lane. The fits into the "Specific binding with Hill slope" were done using GraphPad Prism version 7.00.

\section{Yeast two-hybrid (Y2H) system}

Y2H experiments were carried out as previously described (Malyavko and Dontsova, 2020). 


\section{ACKNOWLEDGEMENTS}

629 We thank M. Agaphonov (Institute of Experimental Cardiology, Cardiology Research Centre, Moscow, 630 Russia) who kindly provided strains, plasmids and protocols for $H$. polymorpha genetics, A. Arutyunyan 631 (Belozersky Institute of Physico-Chemical Biology, Lomonosov Moscow State University) for CD 632 spectra measurements. The study was supported by the Russian Foundation for Basic Research [13-04633 40199-H, 17-04-01692-A] and Interdisciplinary Scientific and Educational School of Moscow 634 University «Molecular Technologies of the Living Systems and Synthetic Biology». NMR studies were 635 supported by the Russian Science Foundation [19-14-00115]. 


\section{REFERENCES}

Agaphonov M, Romanova N, Choi E-S, Ter-Avanesyan M. 2009. A novel kanamycin/G418 resistance marker for direct selection of transformants in Escherichia coli and different yeast species. Yeast 189-195. doi:10.1002/yea.1741

Agaphonov MO, Trushkina PM, Sohn JH, Choi ES, Rhee SK, Ter-Avanesyan MD. 1999. Vectors for rapid selection of integrants with different plasmid copy numbers in the yeast Hansenula polymorpha DL1. Yeast 15:541-551. doi:10.1002/(SICI)1097-0061(199905)15:7<541::AIDYEA392>3.0.CO;2-G

Alavi S, Ghadiri H, Dabirmanesh B, Moriyama K, Khajeh K, Masai H. 2021. G-quadruplex binding protein Rif1, a key regulator of replication timing. The Journal of Biochemistry 169:1-14. doi:10.1093/jb/mvaa128

Anbalagan S, Bonetti D, Lucchini G, Longhese MP. 2011. Rif1 Supports the Function of the CST Complex in Yeast Telomere Capping. PLoS Genetics 7:e1002024. doi:10.1371/journal.pgen.1002024

Azad GK, Tomar RS. 2016. The multifunctional transcription factor Rap1: a regulator of yeast physiology. Front Biosci (Landmark Ed) 21:918-930. doi:10.2741/4429

Barazas M, Annunziato S, Pettitt SJ, de Krijger I, Ghezraoui H, Roobol SJ, Lutz C, Frankum J, Song FF, Brough R, Evers B, Gogola E, Bhin J, van de Ven M, van Gent DC, Jacobs JJL, Chapman R, Lord CJ, Jonkers J, Rottenberg S. 2018. The CST Complex Mediates End Protection at Double-Strand Breaks and Promotes PARP Inhibitor Sensitivity in BRCA1-Deficient Cells. Cell Reports 23:2107-2118. doi:10.1016/j.celrep.2018.04.046

Bienkiewicz EA, Moon Woody A-Y, Woody RW. 2000. Conformation of the RNA polymerase II Cterminal domain: circular dichroism of long and short fragments. Journal of Molecular Biology 297:119-133. doi:10.1006/jmbi.2000.3545 
Bonetti D, Clerici M, Anbalagan S, Martina M, Lucchini G, Longhese MP. 2010. Shelterin-Like Proteins and Yku Inhibit Nucleolytic Processing of Saccharomyces cerevisiae Telomeres. PLoS Genetics 6:e1000966. doi:10.1371/journal.pgen.1000966

Boulton S. 1996. Identification of a Saccharomyces cerevisiae Ku80 homologue: roles in DNA double strand break rejoining and in telomeric maintenance. Nucleic Acids Research 24:4639-4648. doi:10.1093/nar/24.23.4639

Calvo O, Grandin N, Jordán-Pla A, Miñambres E, González-Polo N, Pérez-Ortín JE, Charbonneau M. 2019. The telomeric Cdc13-Stn1-Ten1 complex regulates RNA polymerase II transcription. Nucleic Acids Res 47:6250-6268. doi:10.1093/nar/gkz279

Chai W, Ford LP, Lenertz L, Wright WE, Shay JW. 2002. Human Ku70/80 associates physically with telomerase through interaction with hTERT. J Biol Chem 277:47242-47247. doi:10.1074/jbc.M208542200

Chandra A. 2001. Cdc13 both positively and negatively regulates telomere replication. Genes \& Development 15:404-414. doi:10.1101/gad.861001

Chapman JR, Barral P, Vannier J-B, Borel V, Steger M, Tomas-Loba A, Sartori AA, Adams IR, Batista FD, Boulton SJ. 2013. RIF1 Is Essential for 53BP1-Dependent Nonhomologous End Joining and Suppression of DNA Double-Strand Break Resection. Molecular Cell 49:858-871. doi:10.1016/j.molcel.2013.01.002

Chen H, Xue J, Churikov D, Hass EP, Shi S, Lemon LD, Luciano P, Bertuch AA, Zappulla DC, Géli V, Wu J, Lei M. 2018. Structural Insights into Yeast Telomerase Recruitment to Telomeres. Cell 172:331-343.e13. doi:10.1016/j.cell.2017.12.008

Davé A, Cooley C, Garg M, Bianchi A. 2014. Protein Phosphatase 1 Recruitment by Rif1 Regulates DNA Replication Origin Firing by Counteracting DDK Activity. Cell Reports 7:53-61. doi:10.1016/j.celrep.2014.02.019

de Lange T. 2018. Shelterin-Mediated Telomere Protection. Annu Rev Genet 52:223-247. doi:10.1146/annurev-genet-032918-021921 
Dev H, Chiang T-WW, Lescale C, de Krijger I, Martin AG, Pilger D, Coates J, Sczaniecka-Clift M, Wei W, Ostermaier M, Herzog M, Lam J, Shea A, Demir M, Wu Q, Yang F, Fu B, Lai Z, Balmus G, Belotserkovskaya R, Serra V, O’Connor MJ, Bruna A, Beli P, Pellegrini L, Caldas C, Deriano L, Jacobs JJL, Galanty Y, Jackson SP. 2018. Shieldin complex promotes DNA endjoining and counters homologous recombination in BRCA1-null cells. Nature Cell Biology 20:954-965. doi:10.1038/s41556-018-0140-1

Di Virgilio M, Callen E, Yamane A, Zhang W, Jankovic M, Gitlin AD, Feldhahn N, Resch W, Oliveira TY, Chait BT, Nussenzweig A, Casellas R, Robbiani DF, Nussenzweig MC. 2013. Rifl Prevents Resection of DNA Breaks and Promotes Immunoglobulin Class Switching. Science 339:711-715. doi:10.1126/science.1230624

Escribano-Díaz C, Orthwein A, Fradet-Turcotte A, Xing M, Young JTF, Tkáč J, Cook MA, Rosebrock AP, Munro M, Canny MD, Xu D, Durocher D. 2013. A Cell Cycle-Dependent Regulatory Circuit Composed of 53BP1-RIF1 and BRCA1-CtIP Controls DNA Repair Pathway Choice. Molecular Cell 49:872-883. doi:10.1016/j.molcel.2013.01.001

Evans SK, Lundblad V. 1999. Est1 and Cdc13 as comediators of telomerase access. Science 286:117120. doi:10.1126/science.286.5437.117

Frit P, Ropars V, Modesti M, Charbonnier JB, Calsou P. 2019. Plugged into the Ku-DNA hub: The NHEJ network. Progress in Biophysics and Molecular Biology 147:62-76. doi:10.1016/j.pbiomolbio.2019.03.001

Garvik B, Carson M, Hartwell L. 1995. Single-stranded DNA arising at telomeres in cde13 mutants may constitute a specific signal for the RAD9 checkpoint. Molecular and Cellular Biology 15:6128-6138. doi:10.1128/MCB.15.11.6128

Grandin N. 2001. Ten1 functions in telomere end protection and length regulation in association with Stn1 and Cdc13. The EMBO Journal 20:1173-1183. doi:10.1093/emboj/20.5.1173 
712 Grandin N, Reed SI, Charbonneau M. 1997. Stn1, a new Saccharomyces cerevisiae protein, is implicated in telomere size regulation in association with Cdc13. Genes \& Development

Gravel S. 1998. Yeast Ku as a Regulator of Chromosomal DNA End Structure. Science 280:741-744. doi:10.1126/science. 280.5364 .741

Gupta R, Somyajit K, Narita T, Maskey E, Stanlie A, Kremer M, Typas D, Lammers M, Mailand N,

Hardy CF, Sussel L, Shore D. 1992. A RAP1-interacting protein involved in transcriptional silencing and telomere length regulation. Genes \& Development 6:801-814. doi:10.1101/gad.6.5.801

Hass EP, Zappulla DC. 2015. The Ku subunit of telomerase binds Sir4 to recruit telomerase to lengthen telomeres in S. cerevisiae. eLife 4. doi:10.7554/eLife.07750

Henry YA, Chambers A, Tsang JS, Kingsman AJ, Kingsman SM. 1990. Characterisation of the DNA binding domain of the yeast RAP1 protein. Nucleic Acids Res 18:2617-2623. doi:10.1093/nar/18.9.2617

Hiraga S -i., Alvino GM, Chang F, Lian H -y., Sridhar A, Kubota T, Brewer BJ, Weinreich M, Raghuraman MK, Donaldson AD. 2014. Rif1 controls DNA replication by directing Protein Phosphatase 1 to reverse Cdc7-mediated phosphorylation of the MCM complex. Genes \& Development 28:372-383. doi:10.1101/gad.231258.113

Kang HA, Sohn J-H, Agaphonov MO, Choi E-S, Ter-Avanesyan MD, Rhee SK. 2005. Development of Expression Systems for the Production of Recombinant Proteins in Hansenula polymorpha DL-1 In: Gellissen G, editor. Hansenula Polymorpha. Weinheim, FRG: Wiley-VCH Verlag GmbH \& Co. KGaA. pp. 124-146. doi:10.1002/3527602356.ch9 
Kanoh J, Ishikawa F. 2001. spRap1 and spRif1, recruited to telomeres by Taz1, are essential for telomere function in fission yeast. Current Biology 11:1624-1630. doi:10.1016/S09609822(01)00503-6

Kanoh Y, Matsumoto S, Fukatsu R, Kakusho N, Kono N, Renard-Guillet C, Masuda K, Iida K, Nagasawa K, Shirahige K, Masai H. 2015. Rif1 binds to G quadruplexes and suppresses replication over long distances. Nature Structural \& Molecular Biology 22:889-897. doi:10.1038/nsmb.3102

Kozlowski LP, Bujnicki JM. 2012. MetaDisorder: a meta-server for the prediction of intrinsic disorder in proteins. BMC Bioinformatics 13. doi:10.1186/1471-2105-13-111

Kushnirov VV. 2000. Rapid and reliable protein extraction from yeast. Yeast 16:857-860. doi:10.1002/1097-0061(20000630)16:9<857::AID-YEA561>3.0.CO;2-B

Larcher MV, Pasquier E, MacDonald RS, Wellinger RJ. 2016. Ku Binding on Telomeres Occurs at Sites Distal from the Physical Chromosome Ends. PLOS Genetics 12:e1006479. doi:10.1371/journal.pgen.1006479

Lee JJ, Lee J, Lee H. 2020. Alternative paths to telomere elongation. Seminars in Cell \& Developmental Biology S108495211930120X. doi:10.1016/j.semcdb.2020.11.003

Levy DL, Blackburn EH. 2004. Counting of Rif1p and Rif2p on Saccharomyces cerevisiae Telomeres Regulates Telomere Length. Mol Cell Biol 24:10857-10867. doi:10.1128/MCB.24.24.1085710867.2004

Li S, Makovets S, Matsuguchi T, Blethrow JD, Shokat KM, Blackburn EH. 2009. Cdk1-Dependent Phosphorylation of Cdc13 Coordinates Telomere Elongation during Cell-Cycle Progression. Cell 136:50-61. doi:10.1016/j.cell.2008.11.027

Lim CJ, Cech TR. 2021. Shaping human telomeres: from shelterin and CST complexes to telomeric chromatin organization. Nat Rev Mol Cell Biol. doi:10.1038/s41580-021-00328-y 
Lin J-J, Zakian VA. 1996. The Saccharomyces CDC13 protein is a single-strand TG1-3 telomeric DNA-binding protein in vitro that affects telomere behavior in vivo. Proceedings of the National Academy of Sciences 93:13760-13765. doi:10.1073/pnas.93.24.13760

Lopez CR, Ribes-Zamora A, Indiviglio SM, Williams CL, Haricharan S, Bertuch AA. 2011. Ku must load directly onto the chromosome end in order to mediate its telomeric functions. PLoS Genet 7:e1002233. doi:10.1371/journal.pgen.1002233

Malyavko AN, Dontsova OA. 2020. The telomeric Cdc13 protein from yeast Hansenula polymorpha. Acta Naturae 12:84-88. doi:10.32607/actanaturae.10944

Malyavko AN, Petrova OA, Zvereva MI, Dontsova OA. 2019. Functional duplication of Rap1 in methylotrophic yeasts. Scientific Reports 9. doi:10.1038/s41598-019-43595-8

Marcand S. 1999. Progressive cis-inhibition of telomerase upon telomere elongation. The EMBO Journal 18:3509-3519. doi:10.1093/emboj/18.12.3509

Marcand S, Gilson E, Shore D. 1997. A Protein-Counting Mechanism for Telomere Length Regulation in Yeast. Science 275:986-990. doi:10.1126/science.275.5302.986

Mattarocci S, Reinert JK, Bunker RD, Fontana GA, Shi T, Klein D, Cavadini S, Faty M, Shyian M, Hafner L, Shore D, Thomä NH, Rass U. 2017. Rif1 maintains telomeres and mediates DNA repair by encasing DNA ends. Nature Structural \& Molecular Biology 24:588-595. doi:10.1038/nsmb.3420

Mattarocci S, Shyian M, Lemmens L, Damay P, Altintas DM, Shi T, Bartholomew CR, Thomä NH, Hardy CFJ, Shore D. 2014. Rif1 Controls DNA Replication Timing in Yeast through the PP1 Phosphatase Glc7. Cell Reports 7:62-69. doi:10.1016/j.celrep.2014.03.010

Mersaoui SY, Wellinger RJ. 2019. Fine tuning the level of the Cdc13 telomere-capping protein for maximal chromosome stability performance. Current Genetics 65:109-118. doi:10.1007/s00294-018-0871-3 
Mirman Z, Lottersberger F, Takai H, Kibe T, Gong Y, Takai K, Bianchi A, Zimmermann M, Durocher D, de Lange T. 2018. 53BP1-RIF1-shieldin counteracts DSB resection through CST- and Pol $\alpha$-dependent fill-in. Nature 560:112-116. doi:10.1038/s41586-018-0324-7

Moretti P, Freeman K, Coodly L, Shore D. 1994. Evidence that a complex of SIR proteins interacts with the silencer and telomere-binding protein RAP1. Genes \& Development 8:2257-2269. doi:10.1101/gad.8.19.2257

Moriyama K, Yoshizawa-Sugata N, Masai H. 2018. Oligomer formation and G-quadruplex binding by purified murine Rif1 protein, a key organizer of higher-order chromatin architecture. Journal of

Noordermeer SM, Adam S, Setiaputra D, Barazas M, Pettitt SJ, Ling AK, Olivieri M, Álvarez-Quilón Z-Y, Hart T, Moffat J, Gingras A-C, Martin A, van Attikum H, Jonkers J, Lord CJ, Rottenberg

Nugent CI, Hughes TR, Lue NF, Lundblad V. 1996. Cdc13p: A Single-Strand Telomeric DNABinding Protein with a Dual Role in Yeast Telomere Maintenance. Science 274:249-252. doi:10.1126/science. 274.5285 .249

Pennock E, Buckley K, Lundblad V. 2001. Cdc13 delivers separate complexes to the telomere for end protection and replication. Cell 104:387-396. doi:10.1016/s0092-8674(01)00226-4

Peterson SE, Stellwagen AE, Diede SJ, Singer MS, Haimberger ZW, Johnson CO, Tzoneva M, Gottschling DE. 2001. The function of a stem-loop in telomerase RNA is linked to the DNA repair protein Ku. Nature Genetics 27:64-67. doi:10.1038/83778

Petreaca RC, Chiu H-C, Eckelhoefer HA, Chuang C, Xu L, Nugent CI. 2006. Chromosome end protection plasticity revealed by Stn1p and Ten1p bypass of Cdc13p. Nat Cell Biol 8:748-755. doi: $10.1038 /$ ncb1430 
Petreaca RC, Chiu H-C, Nugent CI. 2007. The Role of Stn1p in Saccharomyces cerevisiae Telomere Capping Can Be Separated From Its Interaction With Cdc13p. Genetics 177:1459-1474. doi:10.1534/genetics.107.078840

Polotnianka RM, Li J, Lustig AJ. 1998. The yeast Ku heterodimer is essential for protection of the telomere against nucleolytic and recombinational activities. Current Biology 8:831-835. doi:10.1016/S0960-9822(98)70325-2

Porter SE, Greenwell PW, Ritchie KB, Petes TD. 1996. The DNA-binding Protein Hdf1p (a Putative $\mathrm{Ku}$ Homologue) Is Required for Maintaining Normal Telomere Length in Saccharomyces Cerevisiae. Nucleic Acids Research 24:582-585. doi:10.1093/nar/24.4.582

Puglisi A, Bianchi A, Lemmens L, Damay P, Shore D. 2008. Distinct roles for yeast Stn1 in telomere capping and telomerase inhibition. EMBO J 27:2328-2339. doi:10.1038/emboj.2008.158

Qi H, Zakian VA. 2000. The Saccharomyces telomere-binding protein Cdc13p interacts with both the catalytic subunit of DNA polymerase alpha and the telomerase-associated est1 protein. Genes Dev 14:1777-1788.

Shay JW, Wright WE. 2019. Telomeres and telomerase: three decades of progress. Nat Rev Genet 20:299-309. doi:10.1038/s41576-019-0099-1

Shepelev NM, Mariasina SS, Mantsyzov AB, Malyavko AN, Efimov SV, Petrova OA, Rodina EV, Zvereva MI, Dontsova OA, Polshakov VI. 2020. Insights into the structure and function of Est3 from the Hansenula polymorpha telomerase. Sci Rep 10:11109. doi:10.1038/s41598-020$68107-\mathrm{x}$

Shi T, Bunker RD, Mattarocci S, Ribeyre C, Faty M, Gut H, Scrima A, Rass U, Rubin SM, Shore D, Thomä NH. 2013. Rif1 and Rif2 Shape Telomere Function and Architecture through Multivalent Rap1 Interactions. Cell 153:1340-1353. doi:10.1016/j.cell.2013.05.007

Shore D, Nasmyth K. 1987. Purification and cloning of a DNA binding protein from yeast that binds to both silencer and activator elements. Cell 51:721-732. doi:10.1016/0092-8674(87)90095-X 
Shubin CB, Greider CW. 2020. The role of Rif1 in telomere length regulation is separable from its role in origin firing. eLife 9:e58066. doi:10.7554/eLife.58066

Shubin CB, Mayangsari R, Swett AD, Greider CW. 2021. Rif1 regulates telomere length through conserved HEAT repeats. Nucleic Acids Research 49:3967-3980. doi:10.1093/nar/gkab206

Shyian M, Albert B, Zupan AM, Ivanitsa V, Charbonnet G, Dilg D, Shore D. 2020. Fork pausing complex engages topoisomerases at the replisome. Genes Dev 34:87-98. doi:10.1101/gad.331868.119

Smekalova EM, Malyavko AN, Zvereva MI, Mardanov AV, Ravin NV, Skryabin KG, Westhof E, Dontsova OA. 2013. Specific features of telomerase RNA from Hansenula polymorpha. $R N A$ 19:1563-1574. doi:10.1261/rna.038612.113

Sohn JH, Choi ES, Kang HA, Rhee JS, Rhee SK. 1999. A family of telomere-associated autonomously replicating sequences and their functions in targeted recombination in Hansenula polymorpha DL-1. J Bacteriol 181:1005-1013.

Sohn JH, Choi ES, Kim CH, Agaphonov MO, Ter-Avanesyan MD, Rhee JS, Rhee SK. 1996. A novel autonomously replicating sequence (ARS) for multiple integration in the yeast Hansenula polymorpha DL-1. Journal of bacteriology 178:4420-4428. doi:10.1128/JB.178.15.44204428.1996

Sreesankar E, Senthilkumar R, Bharathi V, Mishra RK, Mishra K. 2012. Functional diversification of yeast telomere associated protein, Rif1, in higher eukaryotes. BMC Genomics 13:255. doi:10.1186/1471-2164-13-255

Stellwagen AE. 2003. Ku interacts with telomerase RNA to promote telomere addition at native and broken chromosome ends. Genes \& Development 17:2384-2395. doi:10.1101/gad.1125903

Sukackaite R, Jensen MR, Mas PJ, Blackledge M, Buonomo SB, Hart DJ. 2014. Structural and Biophysical Characterization of Murine Rif1 C Terminus Reveals High Specificity for DNA Cruciform Structures. Journal of Biological Chemistry 289:13903-13911. doi:10.1074/jbc.M114.557843 
Teixeira MT, Arneric M, Sperisen P, Lingner J. 2004. Telomere Length Homeostasis Is Achieved via a Switch between Telomerase- Extendible and -Nonextendible States. Cell 117:323-335. doi:10.1016/S0092-8674(04)00334-4

Teng S-C, Chang J, McCowan B, Zakian VA. 2000. Telomerase-Independent Lengthening of Yeast Telomeres Occurs by an Abrupt Rad50p-Dependent, Rif-Inhibited Recombinational Process. Molecular Cell 6:947-952. doi:10.1016/S1097-2765(05)00094-8

Tomida J, Takata K, Bhetawal S, Person MD, Chao H, Tang DG, Wood RD. 2018. FAM 35A associates with REV 7 and modulates DNA damage responses of normal and BRCA 1defective cells. The EMBO Journal 37. doi:10.15252/embj.201899543

Tompa P. 2002. Intrinsically unstructured proteins. Trends in Biochemical Sciences 27:527-533. doi:10.1016/S0968-0004(02)02169-2

Wellinger RJ, Zakian VA. 2012. Everything you ever wanted to know about Saccharomyces cerevisiae telomeres: beginning to end. Genetics 191:1073-1105. doi:10.1534/genetics.111.137851

Wotton D, Shore D. 1997. A novel Rap1p-interacting factor, Rif2p, cooperates with Rif1p to regulate telomere length in Saccharomyces cerevisiae. Genes \& Development 11:748-760. doi:10.1101/gad.11.6.748

Xu D, Muniandy P, Leo E, Yin J, Thangavel S, Shen X, Ii M, Agama K, Guo R, Fox D, Meetei AR, Wilson L, Nguyen H, Weng N, Brill SJ, Li L, Vindigni A, Pommier Y, Seidman M, Wang W. 2010. Rif1 provides a new DNA-binding interface for the Bloom syndrome complex to maintain normal replication. The EMBO Journal 29:3140-3155. doi:10.1038/emboj.2010.186 Repair Using Rif1 to Control 5’ End Resection. Science 339:700-704. doi:10.1126/science.1231573 
A
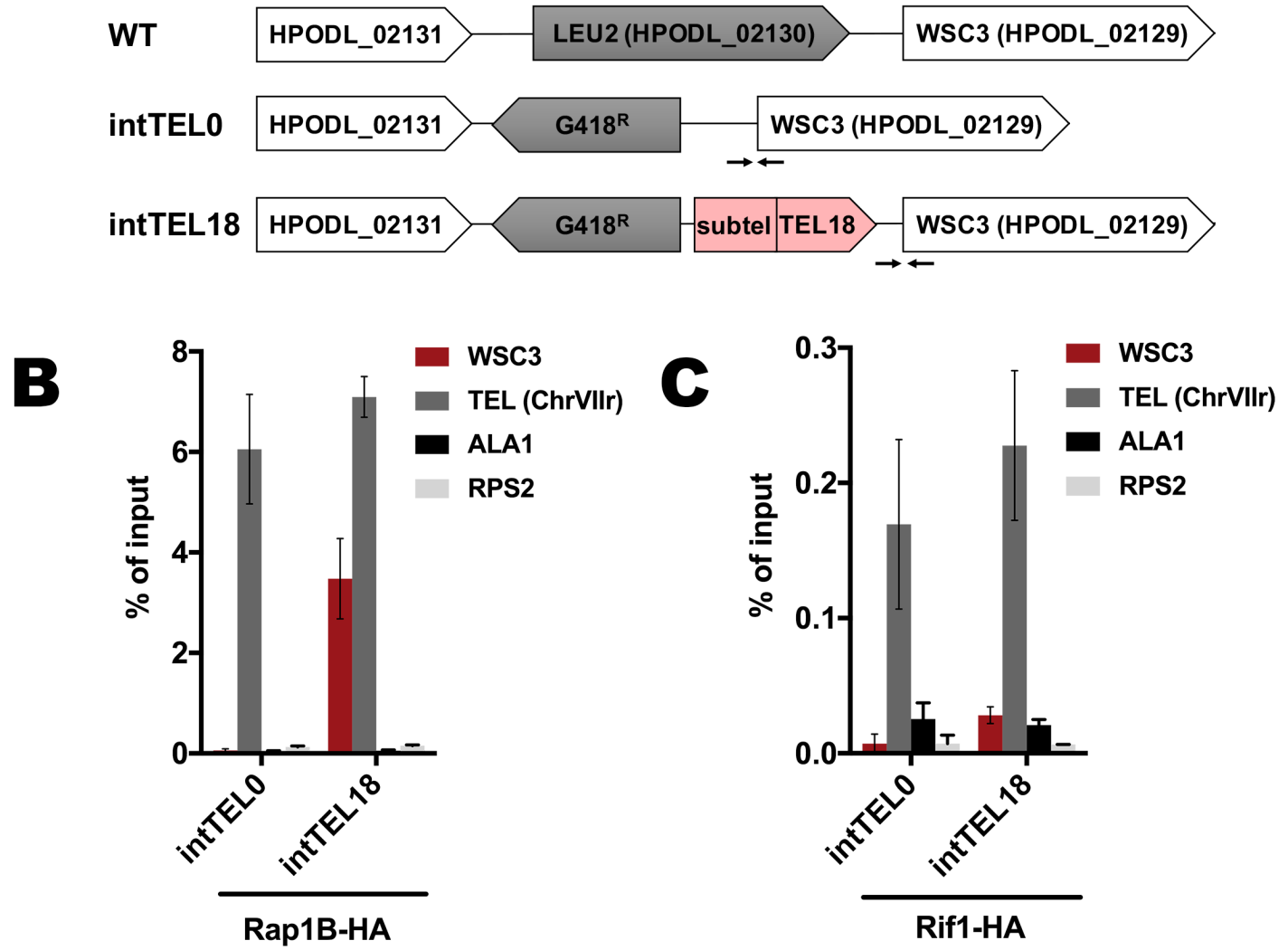

885

Figure 1 - figure supplement 1. (A) Schematic illustration of the leu2 locus on the chromosome I in the WT, intTEL0 and intTEL18 strains. "TEL18" - 18 telomeric repeats, "Subtel" - 304 bp region of the subtelomeric DNA derived from HARS36 (see METHODS). Arrows correspond to qPCR primers targeting the WSC3 gene (located right next to the internal telomeric DNA). (B) ChIP analysis.

Chromatin from the indicated strains was immunoprecipitated on anti-HA magnetic beads. DNA was analyzed by qPCR with primers targeting internal telomeric repeats/WSC3 gene locus ("WSC3"), subtelomere region of the right end of chromosome VII ("TEL"), ALA1 gene locus (negative control, “ALA1”) or RPS2 gene locus (negative control, "RPS2”). The amount of DNA fragments in the IP samples as a percentage of the input DNA was calculated (\% of input). Error bars indicate SD, $\mathrm{n}=3$. (C) same as (B) but with Rif1-HA-containing strains. 
A

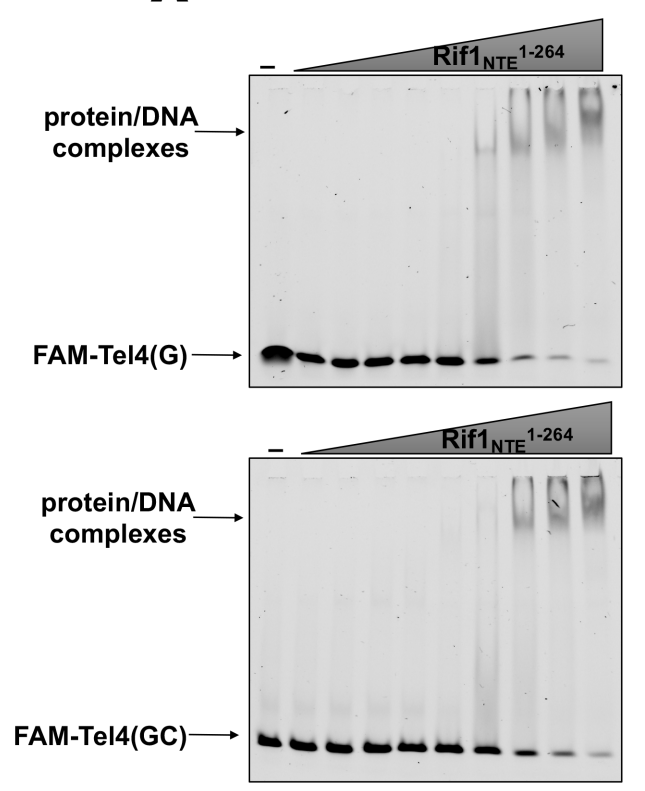

B

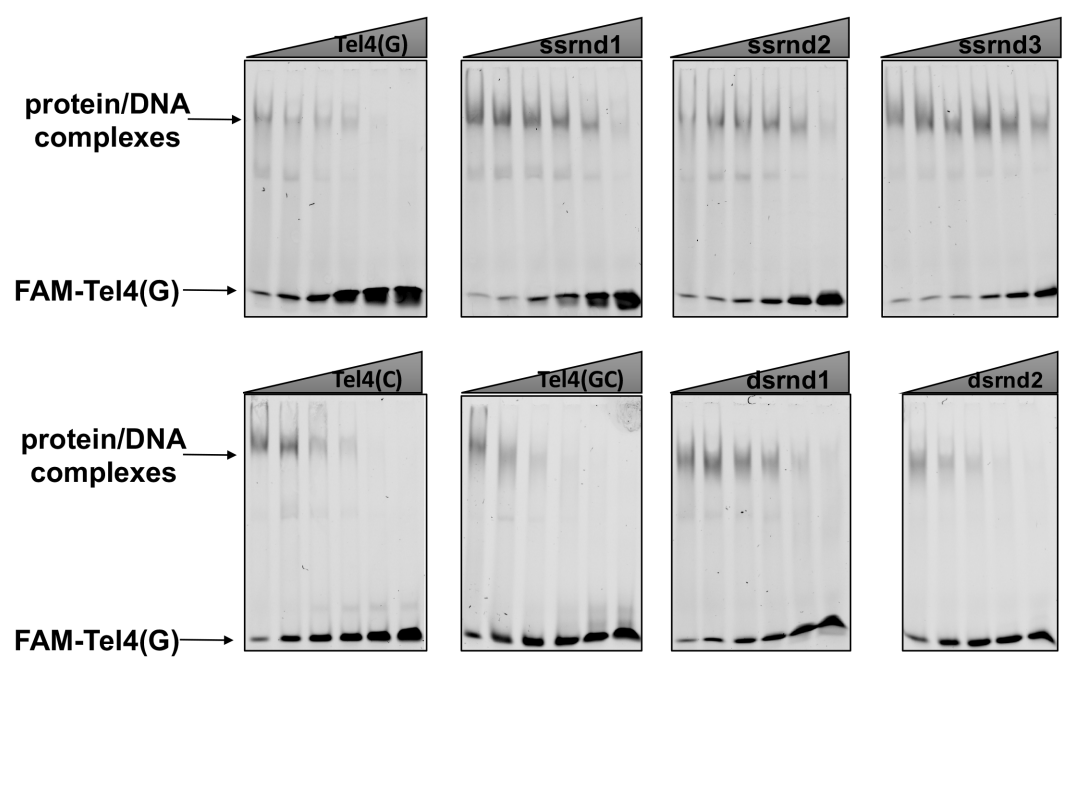

Figure 3 - figure supplement 1. (A) The titration EMSA experiment with increasing concentration of recombinant (tag-free) $\operatorname{Rifl}_{\mathrm{NTE}}^{1-264}(0,1,3,10,30,100,300,1000,3000,10000 \mathrm{nM})$ and $30 \mathrm{nM}$ FAMTel4(G) (upper gel) or FAM-Tel4(GC) (lower gel) as probes. (B) Competition EMSA with $30 \mathrm{nM}$ FAM-Tel4(G), $1 \mu \mathrm{M}$ (tag-free) Rif $1_{\mathrm{NTE}}^{1-264}$ and increasing concentration of the indicated competitor DNA oligonucleotides $(0.1,0.3,1,3,10,30 \mu \mathrm{M})$. 


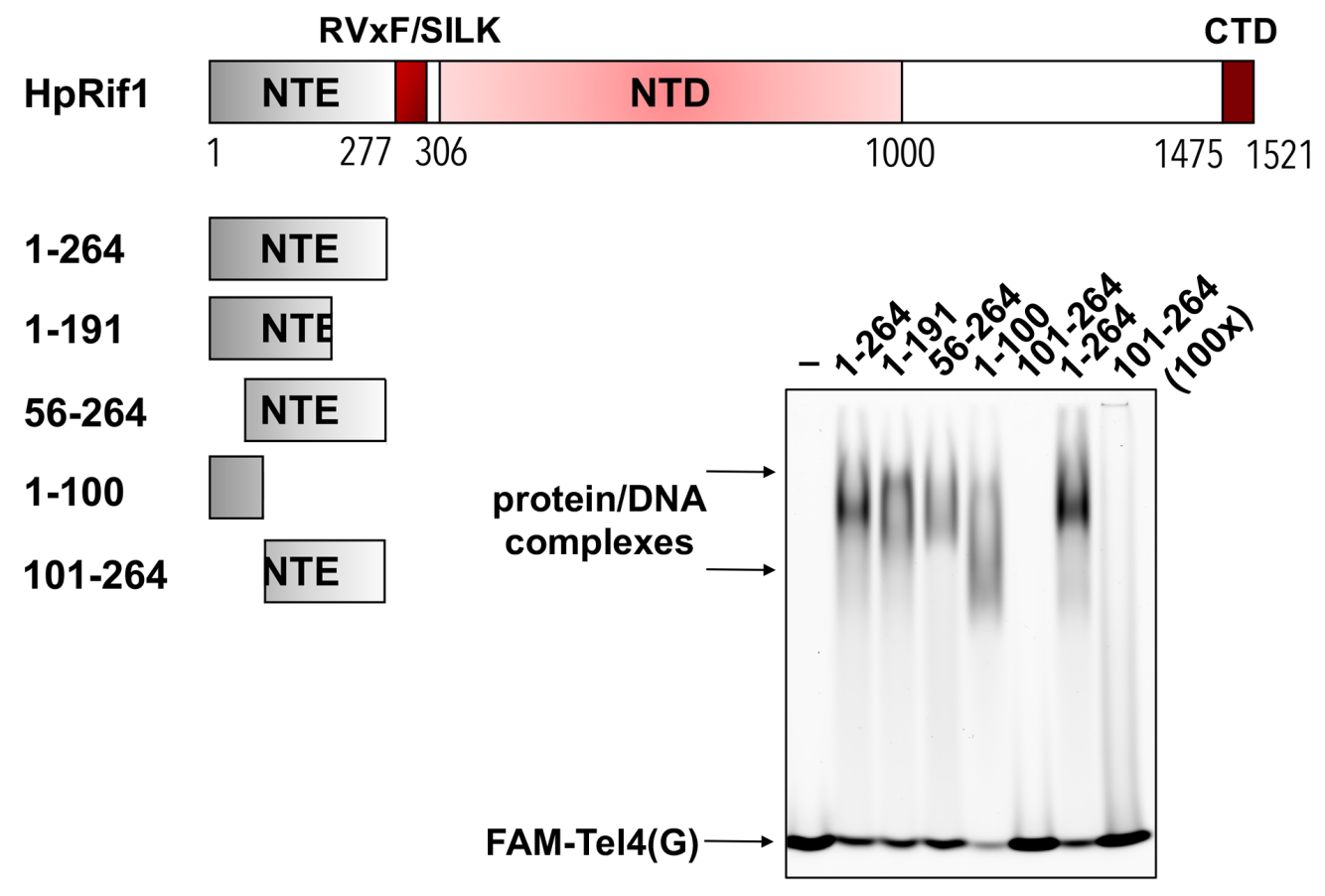

904

905 Figure 4 - figure supplement 1. Rif $1_{\mathrm{NTE}}$ truncation constructs were purified from E. coli as $6 \mathrm{His}-\mathrm{S}-$

906 fusions. $10 \mu \mathrm{M}$ of the indicated fragments were subjected to the EMSA using $1 \mu \mathrm{M}$ of FAM-Tel4(G)

907 probe. "-" - no protein control. "100x" - $100 \mu \mathrm{M}$ of the protein used in the reaction. 
A

\begin{tabular}{|l|l|}
\hline ScRif1 & HpRif1 \\
\hline R401 & K504 \\
\hline K406 & N509 \\
\hline K437 & R539 \\
\hline K451 & S553 \\
\hline K452 & N554 \\
\hline K514 & R607 \\
\hline K518 & V611 \\
\hline H561 & G654 \\
\hline K563 & P656 \\
\hline R565 & K658 \\
\hline K570 & E663 \\
\hline R573 & K666 \\
\hline K680 & N784 \\
\hline R688 & - \\
\hline K689 & - \\
\hline K691 & A791 \\
\hline K692 & Q792 \\
\hline K706 & A805 \\
\hline K708 & D807 \\
\hline
\end{tabular}

B
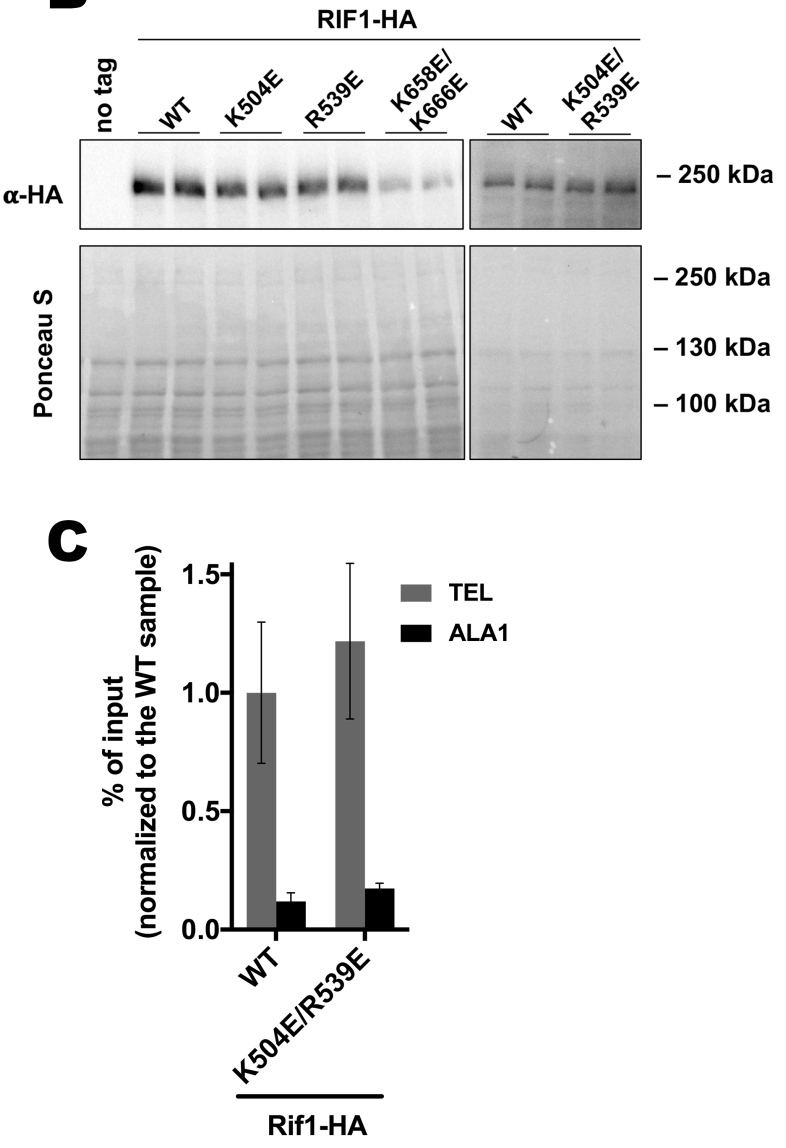

Dif1-HA

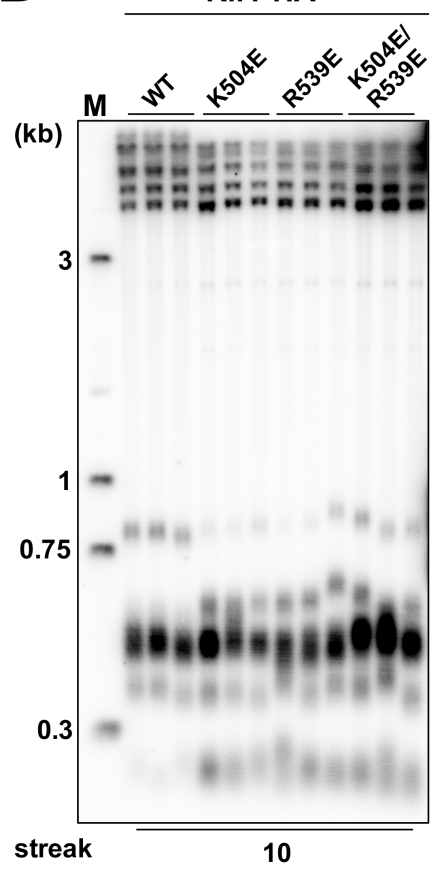

908

909 Figure 4 - figure supplement 2. (A) List of the ScRifl ${ }_{\mathrm{NTD}}$ residues potentially involved in the DNA 910 binding ("ScRif1) and corresponding residues in the HpRif1 ("HpRif1") (alignment in the

911 Supplementary file 1). ScRifl residues which were confirmed to be important for telomeric function are

912 in bold. Conserved residues are marked by red. * - different HpRif1 residues correspond to ScRif1 K514

913 according to alignments with different algorithms. (B) Anti-HA western blot analysis (upper panel).

914 Ponceau S-stained membrane (lower panel) served as a loading control. (C) ChIP analysis of the 915 indicated strains, same as in Figure 1D. (D) Southern blot analysis as in Figure 1B but with different 916 strains. 


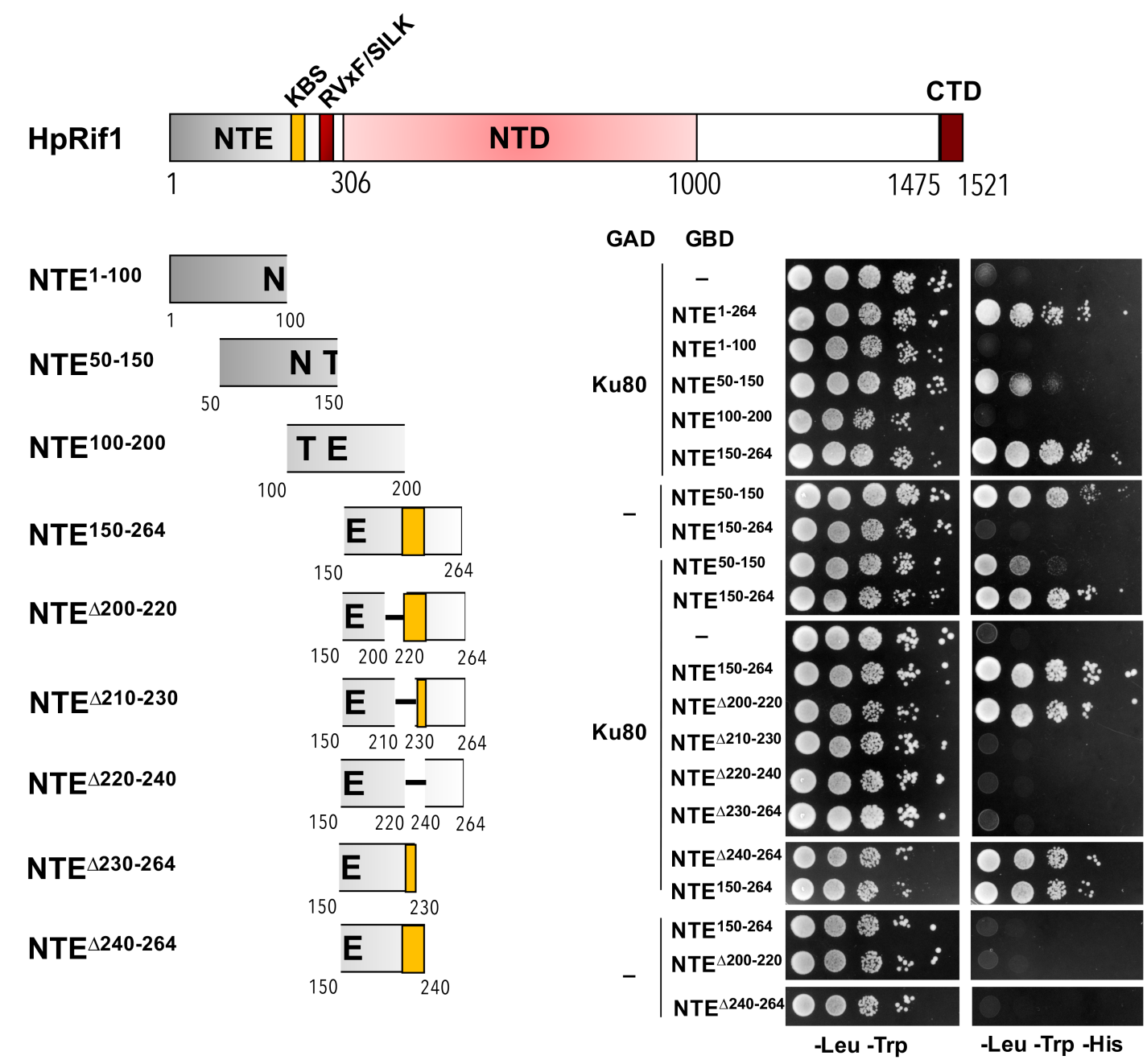

918 Figure 5 - figure supplement 1. Y2H analysis. AH109 colonies expressing pairs of the indicated

919 proteins (fused to either Gal4-BD (GBD) or Gal4-AD (GAD)); cultures with $\mathrm{A}_{600} \sim 0.5$ and four 10-

920 fold serial dilutions were plated on the SC medium lacking amino acids as indicated, and incubated at $92130{ }^{\circ} \mathrm{C}$ for four days. KBS - $\underline{\mathrm{K}} \mathrm{8} 80$ binding $\underline{\text { site. }}$ 

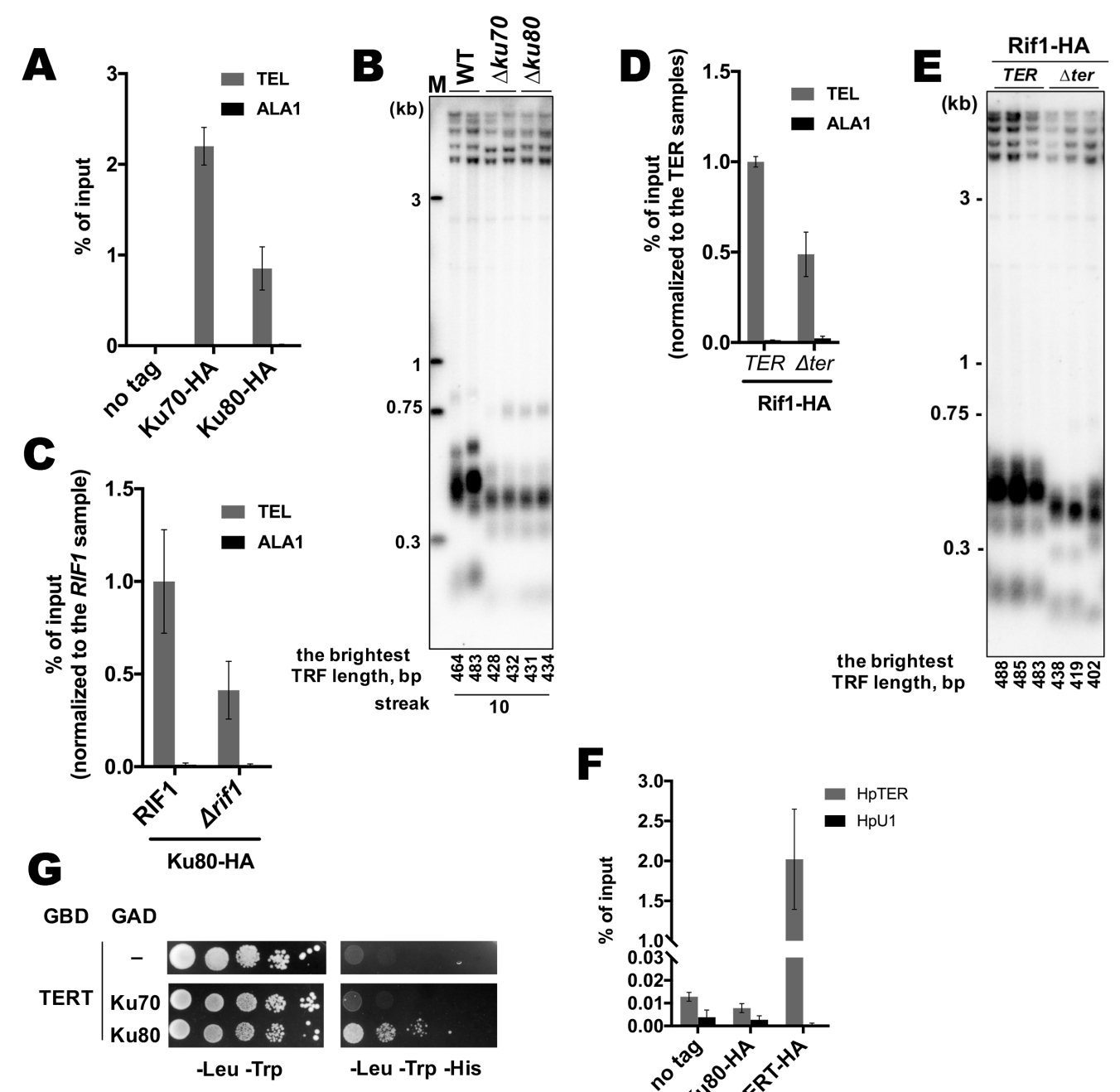

Figure 5 - figure supplement 2. (A) Anti-HA ChIP analysis of the indicated strains, same as in Figure 1D. The 924 amount of DNA fragments in the IP samples is represented as a percentage of the input DNA ( $m e a n \pm \mathrm{SD}, \mathrm{n}=3$ ).

925 (B) Southern blot analysis as in Figure 1B but with different strains. Mean lengths of the brightest TFR bands are: WT $474 \mathrm{bp}, \Delta k u 70430 \mathrm{bp}, \Delta k u 80433 \mathrm{bp}$. WT telomere length reported to be $\sim 160$ bp ( 20 telomeric repeats, (Sohn et al., 1999)), therefore telomere length is reduced by $25 \%$ in each knockout strain. (C, D) Anti-HA ChIP analysis same as (A) (E) Southern blot analysis (as in Figure 1B) of the strains analyzed by ChIP in (D). Mean length of the brightest TFR bands are: TER $485 \mathrm{bp}, \Delta$ ter $420 \mathrm{bp}$ (telomere length is reduced by $\sim 40 \%$ in the $\Delta$ ter strains compared to TER). (F) RNA co-precipitated from the indicated strains on anti-HA agarose was analyzed 931 by qRT-PCR targeting HpTER or snU1 RNA (HpU1). The amount of RNA fragments in the IP samples is 932 represented as a percentage of the input RNA (mean $\pm \mathrm{SD}, \mathrm{n}=3$ ). (G) $\mathrm{Y} 2 \mathrm{H}$ analysis. cultures with $\mathrm{A}_{600} \sim 0.5$ and 933 four 10-fold serial dilutions were plated on the SC medium lacking amino acids as indicated, and incubated at 30 ${ }^{\circ} \mathrm{C}$ for four days. 
A
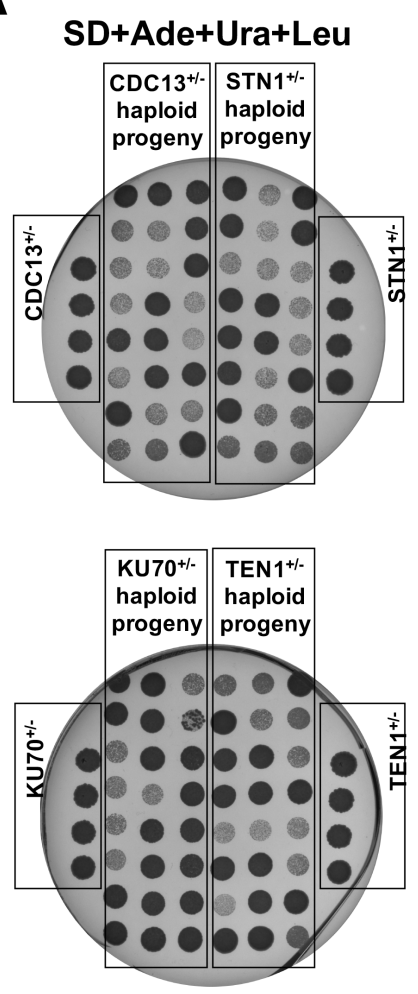

SD+Ade+Ura-Leu
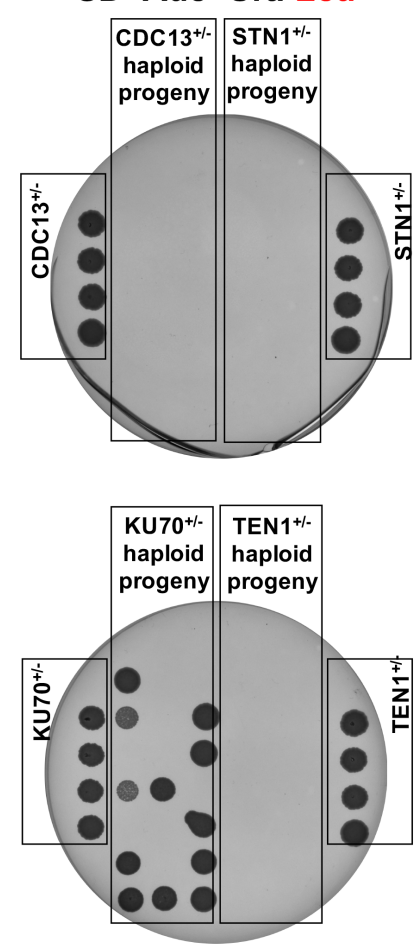

B

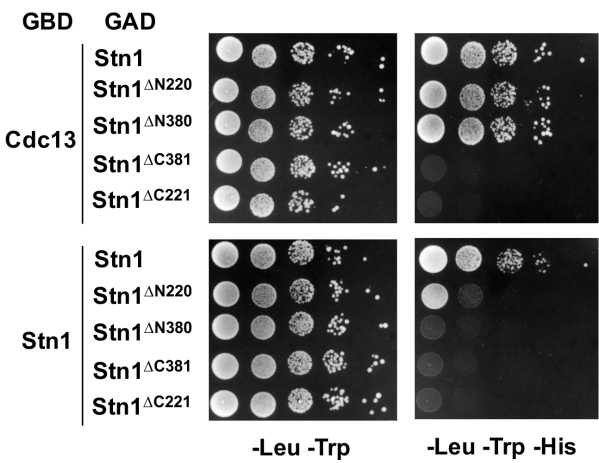
acids as indicated, and incubated at $30^{\circ} \mathrm{C}$ for four days.

Figure 6 - figure supplement 1. (A) Results of the analysis of random spores derived from the indicated heterozygous strains. After ether treatment and growth on YPD plate, 24 colonies derived from each heterozygous strain were randomly picked, resuspended in water, plated onto the indicated selective plates, grown for 4 days at $37^{\circ} \mathrm{C}$ and photographed. Each plate also contained the parental heterozygous strains (phenotype: $\mathrm{Ade}^{+} \mathrm{Ura}^{+} \mathrm{Leu}^{+}$). None of the spores from strains CDC13 ${ }^{+/}$; $\mathrm{STN} 1^{+/-}$ and $\mathrm{TEN}^{+/-}$displayed the $\mathrm{Leu}^{+}$phenotype, whereas $50 \%(12 / 24)$ of the spores from the $\mathrm{KU} 70^{+/-}$had the $\mathrm{Leu}^{+}$phenotype (as expected for the non-essential KU70 gene). (B) Y2H analysis. AH109 colonies expressing pairs of the indicated proteins (fused to either Gal4-BD (GBD) or Gal4-AD (GAD)); cultures with $\mathrm{A}_{600} \sim 0.5$ and four 10-fold serial dilutions were plated on the SC medium lacking amino 


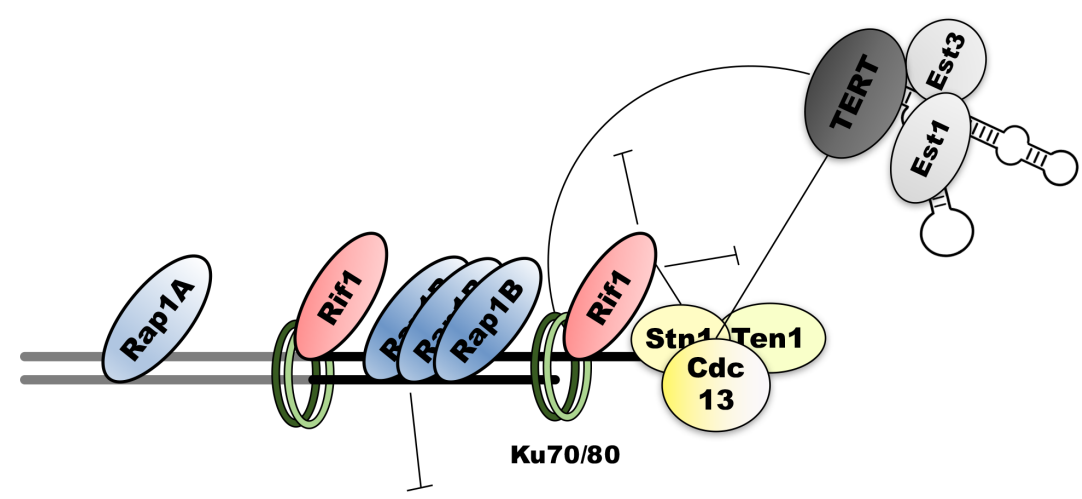

recombination

949 Figure 6 - figure supplement 2. Schematic representation of the putative protein-protein interactions

950 at $H$. polymorpha telomeres. Double thick line represents subtelomeric (gray) and telomeric (black)

951 DNA. Thin lines denote interactions, blunt arrows - inhibitory effect. 